University of Rhode Island

DigitalCommons@URI

Open Access Master's Theses

2017

\title{
Associations Between Weight Dissatisfaction, Fruit and Vegetable Intake, Physical Activity and Personality Traits
}

Katherine Tzepos

University of Rhode Island, ktzepos@my.uri.edu

Follow this and additional works at: https://digitalcommons.uri.edu/theses

\section{Recommended Citation}

Tzepos, Katherine, "Associations Between Weight Dissatisfaction, Fruit and Vegetable Intake, Physical Activity and Personality Traits" (2017). Open Access Master's Theses. Paper 1063.

https://digitalcommons.uri.edu/theses/1063

This Thesis is brought to you for free and open access by DigitalCommons@URI. It has been accepted for inclusion in Open Access Master's Theses by an authorized administrator of DigitalCommons@URI. For more information, please contact digitalcommons-group@uri.edu. 
ASSOCIATIONS BETWEEN WEIGHT DISSATISFACTION, FRUIT AND VEGETABLE INTAKE, PHYSICAL ACTIVITY AND

PERSONALITY TRAITS

BY

KATHERINE TZEPOS

A THESIS SUBMITTED IN PARTIAL FULFILLMENT OF REQUIREMENTS FOR THE DEGREE OF MASTER OF SCIENCE IN NUTRITION AND FOOD SCIENCES

UNIVERSITY OF RHODE ISLAND 
MASTER OF SCIENCE THESIS

OF

KATHERINE TZEPOS

\section{APPROVED:}

Thesis Committee:

Major Professor Geoffrey Greene

Kathleen Melanson

Mary Greaney

Maya Vadiveloo

Nasser H. Zawia

DEAN OF THE GRADUATE SCHOOL 


\begin{abstract}
Background: Weight dissatisfaction is a persons' desire to change his/her current body weight $(1,2)$. Gender differences in weight dissatisfaction in young adults have been observed, where females prefer to achieve slender figures and males strive to gain muscle mass and increase lean body mass (3-6). Personality type may influence body dissatisfaction: for example, people higher on the neuroticism personality trait have a higher level of body dissatisfaction than those higher on the conscientiousness personality trait $(3,7)$. There are also gender differences in behaviors related to body dissatisfaction $(5,8)$. For example, females dissatisfied with their bodies may demonstrate an excessive need to exercise, while males may engage in an excessive weight lifting $(5,9)$. While body dissatisfaction differs from weight dissatisfaction, they are highly correlated $(8,10)$. However, the influencers of weight dissatisfaction have not been fully explored in the literature and it is important to identify how personality traits affect weight dissatisfaction. In addition, research is needed to determine if exercise, fruit and vegetable intake, and affective components of weight perception predict weight dissatisfaction.
\end{abstract}

Objective: The primary objective of this research was to examine the association between personality traits and weight dissatisfaction. The secondary objectives were to examine the association between weight dissatisfaction and moderate and vigorous exercise as well as weight dissatisfaction and fruit and vegetable intake. The exploratory objective was to examine whether weight dissatisfaction was influenced by an accurate perception of weight status. 
Design and Methods: This study was a cross-sectional secondary data analysis using data from the College Environmental Behavioral Perception Survey (CEBPS) to determine if there was an association between weight dissatisfaction, categorized as satisfied and dissatisfied utilizing both operational and affective assessments, and personality, physical activity and fruit and vegetable intake. Undergraduate students at 8 different universities completed the CEBPS survey, $\mathrm{n}=1,838$, which included: weight dissatisfaction, The Five Factor Personality Model to measure personality traits (extraversion, agreeableness, openness to experience, conscientiousness and neutroticism), the International Physical Activity Questionnaire to measure physical activity and the National Cancer Institute Fruit and Vegetable Screener to measure fruit and vegetable intake $(7,11,12)$. To measure the associations between weight dissatisfaction and personality traits, a chi square analysis was completed. For weight dissatisfaction, physical activity and fruit and vegetable intake t-tests were completed. All analyses were conducted separately by gender.

Results: Personality traits as well as fruit and vegetable intake did not predict weight dissatisfaction in either gender. There was no association between weight dissatisfaction and physical activity among female college students. Although there was no association between operational weight dissatisfaction and physical activity in males, using the affective definition, weight dissatisfied males exercised less than weight satisfied males.

Conclusion: Weight dissatisfaction was not associated with personality traits, fruit and vegetable intake and physical activity in general. Additional research is 
needed because the proportion of weight dissatisfied college students was high and intake of fruits and vegetables and physical activity was below recommendations. 


\section{ACKNOWLEDGMENTS}

I am very thankful for everyone who has supported me throughout my experience as a graduate student. I would like to express my deepest gratitude to my major professor, Dr. Geoffrey Greene, who has provided me with support and guidance these last two years. I would also like to thank my committee members Dr. Kathleen Melanson, Dr. Mary Greaney and Dr. Maya Vadiveloo, for their continued guidance throughout this process. Finally, a special thank you to Dr. Cathy English for the endless support and opportunities she has given me throughout the past five years.

I am very grateful for my fellow (past and present) graduate students; thank you for the continuous support. A special thank you to: Marissa Ruginski, Jade White, Tayla Carter, Tracy Lee Miller and Dara LoBuono, for keeping me sane and always being there.

Finally, I would like to thank my friends and family for their constant love and support throughout both my undergraduate and graduate years. Words cannot express how appreciative I am of you. 


\section{TABLE OF CONTENTS}

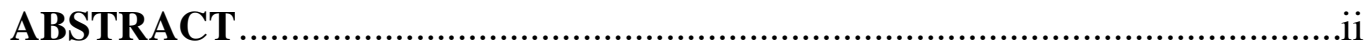

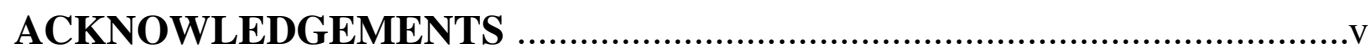

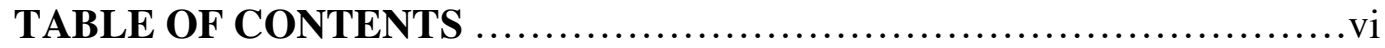

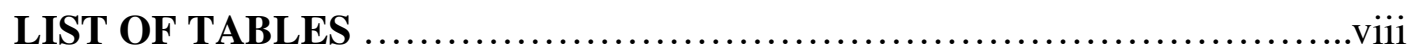

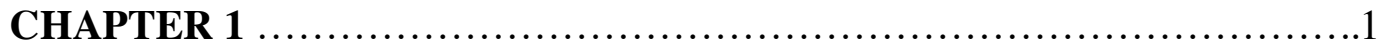

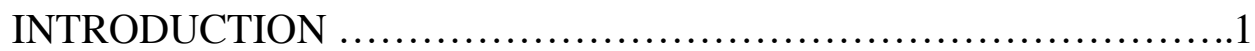

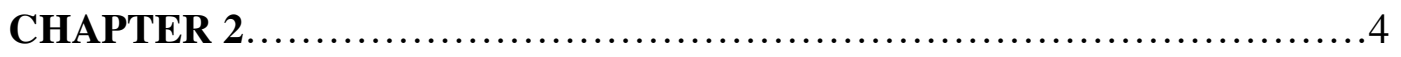

REVIEW OF LITERATURE........................................4

CHAPTER 3 .......................................................... 19

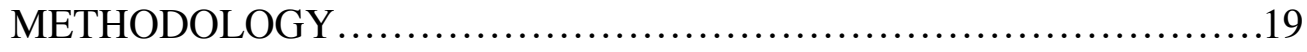

3.1 Participants and Recruitment...........................20

3.2 Measures...............................................21

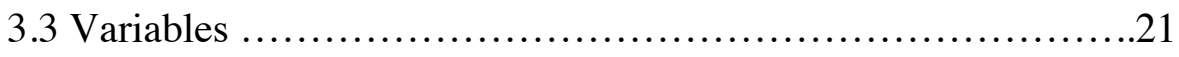

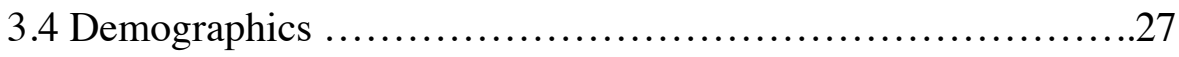

3.5 Data Analyses \& Statistics.................................27

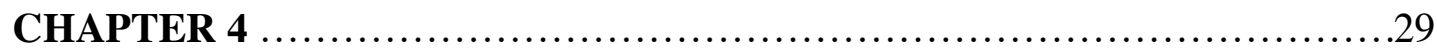

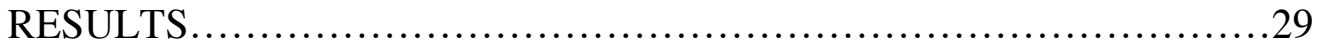

4.1 Demographics.......................................29

4.2 Primary Outcomes.......................................29

4.3 Secondary Outcomes....................................30

4.4 Exploratory Outcomes...................................31

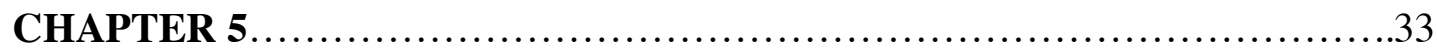


DISCUSSION ................................................... 33

Conclusion and Application......................................38

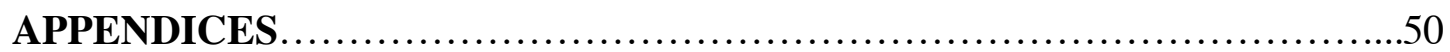

Appendix A- College Environmental Behavioral Perception Survey,

University of Rhode Island........................................50

Appendix B- Additional Analyses....................................87

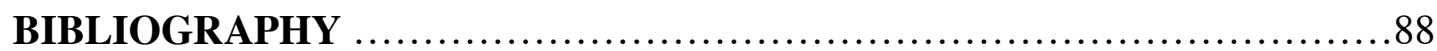




\section{LIST OF TABLES}

TABLE

PAGE

Table 1. Participants' Demographics Characteristics ............................40

Table 2. Proportion by Perceived Body Weight Category by Operational Weight

Dissatisfaction and Satisfaction by Gender..................................41

Table 3. Affective Weight Dissatisfaction and Satisfaction by Gender ...............42

Table 4. Weight Dissatisfaction and Personality Traits by Gender....................43

Table 5. Weight Dissatisfaction and Physical Activity by Gender ....................44

Table 6. Weight Dissatisfaction and Fruit and Vegetable Intake by Gender ..........45

Table 7. Weight Dissatisfaction and Personality Traits, Physical Activity.

Fruit and Vegetable Intake Logistic Regression by Gender ........................46

Table 8. Perception of Weight Status and BMI by Gender.......................47

Table 9. Accurate and Inaccurate Perception of Weight Status

by Normal Weight and Overweight......................................48

Table 10. Comparison of Weight Dissatisfaction by

Operational and Affective Definitions......................................49 


\section{CHAPTER 1}

\section{INTRODUCTION}

College students have been the focus of weight-related research over the past several decades. Over two thirds of college students experience weight gain during their first semester of college, with body fat percentage increasing $1 \%$ during that time (13). The total gain of college students equals about 6.7 pounds and $3.6 \%$ increase in body fat by the time they graduate from college (14).

Weight dissatisfaction is a component of the broader area of body dissatisfaction that includes both weight dissatisfaction and shape dissatisfaction (8). Weight dissatisfaction is defined as a person's desire to change his/her body weight, including affective evaluation of their body weight and a desire to change weight (15). Males and females may experience weight dissatisfaction differently (5). Females tend to strive for a thinner, lighter figure (5). Whereas males tend to have a greater dissatisfaction with perceived lack of muscularity and may want to either increase weight to increase lean body mass or, if obese, males strive for a thinner figure (9). Unfortunately, many young adults engage in unhealthy behaviors to cope with weight dissatisfaction. These behaviors include excessive alcohol use, unhealthy eating, high intake of non-nutrient dense foods, and excessive or minimal physical activity. In order to prevent these behaviors, it is important to better understand the predictors of weight dissatisfaction. Previous research has found that body dissatisfaction is related to specific personality traits, such as neuroticism, diet and exercise, but no studies have looked at these variables in relation to weight dissatisfaction controlling for gender. 
Previous research has assessed the relationship between personality traits and health behaviors. Individuals with extroversion traits are also more likely to be sensation seeking and demonstrate increased alcohol consumption (binge drinking), cigarette smoking and risky sexual behavior (7). Extraversion defined as talkative, assertive and seeking stimulation, has been associated with a positive evaluation of body shape (7). However, research has not assessed personality traits and weight dissatisfaction. Understanding how personality traits may influence weight dissatisfaction is important, because weight dissatisfaction is related to two health outcomes: fruit and vegetable intake and physical activity.

Previous studies have found the majority of college students are not consuming the daily recommended amount of fruits and vegetables; in addition, they have limited variety of fruits and vegetables (16). Two studies found college students who are weight dissatisfied consume a higher proportion of fruit and vegetables than those who are weight satisfied $(13,16)$. The recommendations for fruit and vegetable intake for college students are 2 cups of fruits per day and 3 cups of vegetables per day.

Physical activity has also been examined in the college student population.

Previous research has concluded the college females who experience weight dissatisfaction are more likely to demonstrate an excessive need for exercise (6). For college females, physical activity overall improves satisfaction with body weight (17). College males who experience weight dissatisfaction are more likely to partake in an increase amount of weight lifting (5). Different personality traits, however, have been found to influence inappropriate physical activity, such as over exercising, more than 
others. Therefore, it is important to explore how a personality trait predicts body dissatisfaction in relation to exercise.

Research is limited about the relationship between personality traits and weight dissatisfaction. Although there is some research about the relationship between exercise and personality traits $(5,7,17)$, research is lacking about the relationship between fruit and vegetable intake and personality traits. In addition, the relationship between weight dissatisfaction and personality traits has not been examined while controlling for exercise, fruit and vegetable intake, and gender. It is important to examine weight dissatisfaction in college students to determine the drivers of weight gain and how it relates to weight satisfaction.

The purpose of this study was to examine the relationship between personality traits and weight dissatisfaction controlling for gender, as well as the relationship between physical activity and fruit and vegetable intake with weight dissatisfaction, in college students. This study also examined the relationship between personality traits and weight dissatisfaction controlling for gender, exercise, and fruit and vegetable intake. 
CHAPTER 2

Review of Literature

\section{Background Information: College Students and Weight Changes}

College students have been the focus of weight related research over the past several decades (18-23). Over two-thirds of college students experience weight gain within their first semester of college, with body fat percentage increasing $1 \%$ during that time (13), with a total gain of about 4.38 kilograms $(\mathrm{kg})$ and $1.3 \mathrm{~kg} / \mathrm{m}$ (meters) ${ }^{2}$ in body mass index (BMI) by the time they complete their four years $(14,18)$.

Pope et al., (18) determined that $11.6 \%$ of college students maintained their weight within 2.2 pounds over their four years at college. For this study, incoming college freshman were recruited via mail to their homes during the summer prior to enrollment in college (18). During their first year college their physical activity, height and weight were collected height and weight were then collected at the beginning and end of each of the following semesters for a total of 7 times (18). The same participants were then asked during their senior year to participate in the same anthropometric assessment and health behaviors as their freshman year (18). The average BMI during final semester senior year, $24.84 \mathrm{~kg} / \mathrm{m} 2$, increased from first semester of freshman year, $23.54 \mathrm{~kg} / \mathrm{m} 2$, by $1.3 \mathrm{~kg} / \mathrm{m} 2$ (18).

Webb et al., (21) surveyed incoming freshman prior to enrolling in college. This survey asked basic demographic questions, such as self-reported height and weight, weight expectations regarding weight change from current time to one year and norms and concerns regarding first year weight gain (21). About $88.4 \%$ of the surveyed sample, 341 female high school graduates planning to attend state-funded 
predominately white universities, believed weight gain during the first year of college is normal (21). Nearly half, $42 \%$, of the surveyed participants reported a moderate fear of this weight gain (21).

Lloyd-Richardson et al., (22) assessed 904 college students' weights during their freshman year and sophomore years. Freshman college students reported their weight and height in September. Students were weighed and measured at the end of their first semester and beginning and end of their second year. Students were weighed to the nearest $0.1 \mathrm{~kg}$ using an electronic and their height was measured to the nearest half centimeter using an electric stadiometer (22). College females gained an average of $1.6 \mathrm{~kg}$ over these two years. Males gained an average of $2.5 \mathrm{~kg}$ over two years. Most of the weight gain occurred in the first semester of freshman year (22).

Cluskey et al.,(19) assessed the difference in weight change by gender in 379 freshmen college students over eight weeks from October to December. The majority $(60 \%)$ of participants were male. Students' weight was measured by a waist-high, electronic scale and height by a wall-mounted stadiometer. Weights recorded to the nearest 0.5 pound and height to nearest $1 / 8$ of an inch (19). College males gained more weight with a range of $0.23-12.73 \mathrm{~kg}$ than college females with a range of 0.45-6.62 $\mathrm{kg},(\mathrm{p}<0.001)$ over the eight weeks. College males with an initial BMI in the normal range (46\%) gained an average of $4.5 \mathrm{~kg}(19)$. The $38 \%$ of college males initially in the overweight or obese range gained an average of $2.3 \mathrm{~kg}$ (19). Most females (97\%) were in the normal weight range at the start of the eight weeks.

Racette et al., (23) conducted a longitudinal study assessing 240 participants' weight and height during their first two weeks of freshman year and final two to three 
weeks of senior year. During their freshman year, $80 \%$ of participants were classified as a normal BMI, by the end of their senior year $23 \%$ of those participants originally classified as a normal BMI had a weight increase to the overweight/obese (23). Weight change varied among students from a loss of $13.2 \mathrm{~kg}$ to a gain of $20.9 \mathrm{~kg}$. Body composition was not measured in this study (23). Students during their freshman year completed exercise and diet questionnaires based on the Transtheoretical model; $71 \%$ of students reported being in action or maintenance for exercise, meaning they complete 150 minutes of moderate to vigorous exercise a week and $29 \%$ reported being in action or maintenance for eating at least 5 cups of fruits and vegetables a day (23).

Kelly et al., (20) assessed weight change using an electronic scale and body fat composition using bioimpedance in female college undergraduates at the beginning of freshman year, at 6 months, in March, and at the beginning of sophomore year. Participants were categorized based on their weight change; participants who gained more than 3 pounds were "weight gainers," participants who lost more than 3 pounds were categorized as "weight reducers," and those gaining or losing less than or equal to 3 pounds were "weight maintainers" (20). At baseline "reducers" had a body weight of 141.1 pounds and a body fat percentage of $26.4 \%$ which decreased to a body weight of 133.1 pounds and a body fat percentage of $22.9 \%$ at one year (20). At baseline "gainers" had a body fat percentage of $24.1 \%$ which increased to $27.6 \%$ at one year (20). There were no differences in baseline BMI and body composition between gainers and reducers. Weight change was associated with changes in body fat (20). 
Hendrickse et al., (24) assessed female college students perceptions' of body image. Females students tend to compare themselves to their peers and perceived their peers are thinner (24). This was associated with risky health behaviors, such as restricting food intake or purging developing and low self-esteem (24). Lin et al., (25) assessed male college students' perceptions of body image, muscularity image and steroid use. Over $90 \%$ of the males surveyed wanted to increase muscularity (25). Jackson et al., (26) assessed college body perceptions in college males and females. They found that college females have a desire to be thin whereas college males have a desire to be muscular (26). This desire to change for college students to alter their body composition is related to body dissatisfaction.

\section{Background Information: Body Dissatisfaction and Weight Dissatisfaction Among}

\section{College Students}

A survey completed by the American College Health Association in 2016, found $61 \%$ of college students are trying to change their weight (27). College students tend to have unrealistic weight goals that lead to misperceptions of body image and to body dissatisfaction (14). Body dissatisfaction is a negative evaluation of one's own body, which includes both weight and shape (28). Individuals who experience body dissatisfaction often compare their own bodies to their peers' bodies (28). Body dissatisfaction stems from multiple different environmental and cultural components, including: media body comparison, self-esteem, depressive mood, parent dining environment, friend dining, TV exposure, magazine message exposure, weight teasing and BMI (29). Body dissatisfaction has been closely related to body image, selfesteem and self-image (30). 
College females report greater desire to lose weight and tend to overestimate their actual body weight than males (17). Gunnare et al., (17) found college females are more likely to underreport their weight compared to college males. This inaccurate body weight perception in females is associated with body dissatisfaction, which is associated with dieting and risky weight reduction methods $(31,32)$. College males who experience body dissatisfaction engage in risky behaviors depending on whether dissatisfaction is with a perception of over or under weight. Overweight males tend to diet and binge and may be exercise dependent. Males who perceive they are underweight or under muscular may use food supplements and steroids (33).

Kelly et al. (20), evaluated 131 female undergraduate students at baseline, 6 months and 12 months using the Multidimensional Body Self-Relations Questionnaire, MBSRQ-BAS, for body dissatisfaction. Body dissatisfaction was found not to be a strong predictor of weight change during this year (20).

Ridgeway et al., (34) assessed 30 male undergraduate students with a questionnaire about perceptions of overall body composition and shape and their desired body composition and shape. Body dissatisfaction included muscularity, height and body fat percentage (34). They concluded college males do not have specific characteristics for an ideal body and shape composition (34).

Sira et al., (31) examined the association of body satisfaction with perceived parental care and control, global self-esteem, dieting behavior and BMI. This was demonstrated through self-reported height and weight and the Eating Attitude Test (EAT) questionnaire (31). For college females and males, BMI, self-esteem were found as significant predictors for body satisfaction; maternal control and total EAT 
score were found to be significant predictors of body satisfaction for college females (31). They concluded that both college males and college females experience body dissatisfaction, but in different ways.

\section{Background Information: Weight Dissatisfaction}

Weight dissatisfaction is a component of the broader area of body dissatisfaction that includes both weight dissatisfaction and shape dissatisfaction (8). Weight dissatisfaction is defined as a person's desire to change their body weight, including operational and affective evaluation of their body weight (15).

Males and females experience weight dissatisfaction differently (5). Females tend to focus on body weight striving for a thinner, lighter figure (5). Males tend to have a perceived lack of muscularity and normal weight and some overweight males tend to want to increase weight to increase lean body mass. Obese males generally strive for a thinner figure (9). Similar to body dissatisfaction, many young adults engage in unhealthy behaviors when dissatisfied with their body weight $(5,6)$. These behaviors include unhealthy eating and excessive or minimal physical activity $(1,5,6,35)$.

Greene et al., (1) identified clusters (homogenous subgroups) of college males and females $(n=1,689)$ in Project WebHealth, a weight gain prevention intervention study. Participants completed the Three-factor Eating Questionnaire, Eating Competence Inventory, NCI Fruit and Vegetable Screener and the International Physical Activity Questionnaire. Participants also reported height and weight and answered the question “how much would you like to weigh?”. Participants' anthropometric measurements were also obtained using a digital or balance beam scale and a wall-mounted stadiometer. Both males and females classified in the high-risk cluster had the highest 
BMI and waist circumference as well as desired a greater amount of weight loss and has the highest emotional eating scores compared to the two lower-risk clusters. Female participants in this cluster desired an average weight loss of 18.8 pounds and male participants desired an average weight loss of 11.3 pounds. In addition, female participants in the high-risk cluster consumed the least amount of fruits and vegetables. This study found most female participants (90\%) desired to lose weight whereas male participants were split between a desire for weight loss, weight maintenance, and weight gain (1).

Palmer assessed weight dissatisfaction in college students using 15-month outcome data from Project WebHealth (35). Affective evaluation and quantification of weight dissatisfaction were combined to define weight dissatisfaction. The affective weight dissatisfaction variable assessed participants current weight satisfaction, asking participants to think about their current weight and rate if they are 1=happy with current weight, $2=$ don't care about current weight or $3=$ upset about their current weight which was converted to a 3 -point scale $1=$ =positive evaluation, $2=$ neutral evaluation, $3=$ negative evaluation. Desired weight change was quantified using the items, "What is your current weight?" and "What would you like your current weight to be?" (35). Desired weight change was determined by subtracting desired weight from reported weight the converted into a percentage of current body weight (absolute value of desired weight change/current weight*100). There was no difference between genders in in desired weight change; females on average desired to lose 7-8\% of body weight and college males desired to gain or lose an average of 5-6\% of body weight (35). Participants were evaluated over three different time points; baseline, 3 months 
and 15 months. No significant relationship was found between weight dissatisfaction and weight change over time.

Jaworowska et al., (36) assessed weight dissatisfaction of 178 pharmacy students. A trained individual measured height and weight. Students were classified into four categories of BMI (36). Participants were self-reported current weight, body image and diet practices (36). Participants self-classified as: "underweight", "normal weight", "overweight" or "obese.” They responded to an item about whether they were trying to lose weight with possible responses of "yes" or "no." Another item assessed if their desired body weight was "less", "the same" or "increased" from their current weight (36). This study concluded a substantial proportion of pharmacy college students misperceived their actual weight (36). Around two-thirds of normal weight females wanted to lose weight while one-third of normal weight males wanted to gain weight (36).

Gunnare et al., (17) surveyed 405 participants in a cross-sectional study. Participants self-reported their height and weight prior to researchers measuring height and weight (17). Participants were asked: "How satisfied are you with your current body weight?" and "How often do you weigh yourself?" (17). This study concluded participants overestimated their height and underestimated their weight (17). A higher BMI, female gender and greater amount of physical activity were associated with less accuracy of reported body weight (17). The greater the amount of physical activity reported, the less accurate the self-reported weight (17).

Harris et al., (37) surveyed 89 nutrition and exercise science majors with the EAT questionnaire and the exercise dependence scale. Weight dissatisfaction was 
determined based on the difference between reported current and ideal BMI (37). Eighty-seven of the 89 participants in this study were defined as being weight dissatisfied (37). Research is needed to better understand what the predictors of weight dissatisfaction are in order to encourage healthier weight management practices in this population, such as, increasing intake of fruits and vegetables, as well as determine any preexisting notion, such as, dominant personality traits (37).

\section{Background: Personality Traits}

Personality traits are stable characteristics of an individual that can be shown to predict individual decision-making or life outcomes (38). Personality traits are a way to categorize how a person feels, thinks and behaves (38). The big five personality traits include: openness, conscientiousness, extraversion, agreeableness and neuroticism (39). Conscientiousness includes striving for competence and achievement, being disciplined, orderly, reliable and deliberative $(38,39)$. Extraversion incudes being talkative, assertive and seeking stimulation $(38,39)$. Neuroticism includes experiencing unpleasant and negative emotions (fear, anxiousness, pessimism, sadness, insecurity) $(38,39)$. Agreeableness includes being courteous, good-natured, cooperative, tolerant and compassionate $(38,39)$. In order to determine an individual's dominant personality trait, psychologists have created reliable and valid instruments (40). A validated instrument shown to be a predictor of the big five personality traits is the ten-item personality measure (39).

Each personality trait relates to health behaviors in different ways (39). For example, people with the dominant personality trait of extroversion are more likely to be sensation seeking and demonstrate increased alcohol consumption (binge drinking), 
cigarette smoking and risky sexual behavior (7). The participants with the personality trait of neuroticism also tend to increase their alcohol consumption and binge drinking more than their peers. Agreeableness is associated with a decrease in alcohol use disorders (7).

\section{Personality Traits \& Weight}

To our knowledge no previous research has been completed regarding personality traits and weight dissatisfaction in college students. However previous research has been conducted with body dissatisfaction, weight status and personality traits. The dominant personality trait of extroversion has been associated with a positive evaluation of body shape (7) and extroverts see themselves accurately in regards to shape: pear, hourglass, rectangle or apple (41). Previous research has determined extroverted females evaluate their physical appearance more positively than the other personality traits (42).

Allen et al., (43) conducted a meta analysis of 31 studies of personality traits and body perception. Two-thirds of the articles examined found an association between neuroticism and negative body perception for both males and females (43). Females with the dominant personality trait of neuroticism are less satisfied with their physical appearance than those with other traits. In addition, they report a greater weight discrepancy comparing actual to desired body weight and a higher body weight misperception comparing measured to reported weight than other traits (6). Neuroticism has been linked to increased body dissatisfaction with muscularity in males $(6$, Hartmann, 2015 \#10, 44). Males with the dominant personality trait of 
neuroticism also have a lower satisfaction with body image and higher body weight misperception than other traits (6).

Not all personality traits are connected with body dissatisfaction and weight status. The personality traits of conscientiousness, agreeableness and openness are not associated with strong affective components of self-evaluation of weight status (43). Previous research found conflicting results for the dominant personality trait of conscientiousness $(43,45)$. This may be related to the high self-confidence level of individuals with conscientiousness as well as their eating habits and body weight (43, 45). One study by Frederick et al., (6) found individuals with the dominant personality trait of conscientiousness had a greater satisfaction with appearance and weight than those with other traits. Another study found that individuals who are conscientious are more likely to maintain a healthy weight and to follow healthy eating habits (46). Previous research assessed BMI and the Big five personality traits and found that personality traits are not related to BMI (47).

\section{Background: Physical Activity}

Physical activity is an important component of overall health (48). Physical activity is defined as bodily movement caused by skeletal muscles that result in an increased energy expenditure; this bodily movement includes incidental movement, daily walking, and persistent exercise (49). Physical activity recommendations for college students include an average of 150 minutes of moderate intensity or 75 minutes of vigorous activity weekly (48). Based on the American College Health Association, National College Health Assessment (27), Spring 2016, 60\% of college females and 55\% of college males reported doing at least 30 minutes of moderately 
intensity activity at least once in the last 7 days. College students. In addition, $46 \%$ of female and $51 \%$ of male met the guidelines' for moderate to vigorous activity in the last 7 days (27).

\section{Physical Activity \& Weight}

Physical activity improves satisfaction with body weight for college females (17) but college females who experience weight dissatisfaction demonstrate an excessive need for exercise (6). College males who experience weight dissatisfaction are more likely to engage in weight lifting than weight satisfied males (5). Perceptions of body weight have been found to be both motivators and barriers for physical activity $(50,51)$.

Anton et al., (52) assessed the relationship between physical activity and body discrepancy, the difference between reported and ideal weight, in 115 female college students. Participants were asked to list their actual weight and their ideal weight and a body discrepancy score was calculated. In addition, a physical activity questionnaire was completed (52). This study found an inverse relationship between the body discrepancy score and physical activity levels; higher levels of body discrepancy were associated with lower levels of physical activity (52).

\section{Personality Traits \& Physical Activity}

Previous research found a relationship between dominant personality traits and physical activity. A person with the dominant personality trait of extroversion is more likely to exercise than those with other personality traits (53). This is related to sociability and excitement seeking which may motivate extroverts to follow through with exercise (53). Extroversion is related to seeking out physical activity exercises; 
individuals with extroversion are more likely to be look for situations that offer opportunities to be physically active than those with other traits (54).

The personality trait of neuroticism is generally associated with a decrease in exercise (7). Previous research found individuals with the dominant personality trait of neuroticism tend to be more anxious and self-conscious, limiting their ability to be physically active and to take advantage of the different opportunities that arise $(7,54)$. However Lu et al., (55) has found resilience could moderate this effect.

Individuals with the personality trait of conscientiousness are more motivated to fulfill their exercise intentions, because they are goal striving, organized, deliberate and self-disciplined $(54,56)$. There is no relationship between the personality trait of agreeableness and exercise behavior (7). Previous research has concluded majority of college students do not meet the recommendations for physical activity(7).

\section{Background: Fruit \& Vegetable Intake}

Fruit and vegetables are low energy, nutrient dense food options (16).

Recommendations for college males and females are 2 cups of fruit per day and 3 cups of vegetables per day (27). Previous research has examined college students' daily fruit and vegetable intake, and found that two-thirds college students are not consuming the daily recommended amount of fruits and vegetables, and when they do consume these foods they tend to be the same ones (16). However, student diets tend to be low in in fiber, vitamin $\mathrm{A}, \mathrm{C}$, and $\mathrm{E}$, folate and calcium and are higher in sodium, cholesterol, fat and saturated fat (57).

Nix et al., (58) assessed college students' barriers to consuming adequate amounts of fruits and vegetables. The barriers of focus were: message delivery to 
include both a fruit and vegetable message and a social normative message, and attitudes of peers (58). Students underestimated their peers' intake of fruits and vegetables by about one cup (58). The majority of students felt they consumed enough fruits and vegetables even though their intake was below than the recommended amounts (58).

\section{Fruit \& Vegetable Intake \& Weight}

College students who consume the recommended amount of fruits and vegetables daily tend to have a lower body weight than those who do not (16). Previous research has determined college students who are weight dissatisfied consume a higher proportion of fruit and vegetables than those who are weight satisfied $(16,57)$.

\section{Fruit \& Vegetable Intake \& Personality Traits}

Previous research has determined specific personality traits to be associated with eating behavior and fruit and vegetable consumption. Individuals with the personality trait of neuroticism tend to overeat on high-energy dense foods to compensate for negative emotions $(6,56)$. The trait of openness is the strongest predictor of eating practices among the five personality traits (59). However, individuals with the personality trait conscientiousness tend to follow healthy eating practices (59).

\section{Accurate Perception of Weight}

Perception of weight status is an issue for adolescents and college students $(60$, 61). Sampasa-Kanyiga et al., (62) found an association between perception and attitudes of body weight in adolescents. This study concluded participants who perceived themselves as overweight/obese have lower odds to adhere to physical 
activity recommendations than participants who perceive themselves as normal body weight (62). Another study found that one-third of obese Chinese American adolescents did not perceive their body weight correctly (63). Tanenbaum et al., (64) found slightly under half of 902 female college students in their study (46\%) had an inaccurate perception of weight status. In addition, $69.2 \%$ of the college females categorized themselves as overweight or obese but only $6.7 \%$ had a BMI over 25 $\mathrm{kg} / \mathrm{m}^{2}(64)$.

Previous research has found women are more likely to have an accurate weight perception than men, possibly because women are more likely to be involved in weight control behaviors (65).

\section{Summary}

This literature review has provided a review of weight dissatisfaction in college males and females. The review has also examined the research behind weight change, body dissatisfaction, fruit and vegetable intake, physical activity and accurate perception of weight status in college students. There are multiple studies that examine body dissatisfaction and personality traits in college students $(6,7,41,43)$, however

there are very few studies that examine weight dissatisfaction and personality traits in this population. This secondary data analysis will add to the literature on weight dissatisfaction in college students by exploring weight dissatisfaction with personality traits, fruit and vegetable intake and physical activity. 


\section{CHAPTER 3}

\section{Methodology}

\section{College Environmental Behavioral Perception Survey}

This study utilized data collected with the College Environmental Behavioral Perception Survey (CEBPS), a self-administered survey assessing health and nutrition related-behaviors among undergraduate college students at eight participating universities.

\section{Measures}

For this study weight dissatisfaction was defined by three self-reported items, "How do you describe your weight", "What are you trying to do about your weight?" "How do you feel about your current weight?" The first two items were combined for an operational definition of weight dissatisfaction and the third item was used for an affective definition of weight dissatisfaction. Personality traits were defined based on Gosling et al.'s brief measure (39). Exercise was assessed as minutes of moderate to vigorous physical activity per week based on the International Physical Activity Questionnaire (IPAQ) $(11,12)$ and fruit and vegetables consumed a day were measured by the NCI Fruit and Vegetable Screener (12). This study design was a cross-sectional, descriptive secondary data analyses design.

Weight dissatisfaction was the independent variable, and personality traits, physical activity, fruit and vegetable consumption, BMI and perception of weight status were dependent variables. Due to the differences found between genders (17, $18,22)$, all analyses were completed separately by gender. The primary hypothesis was that participants with weight dissatisfaction were more likely to have personality 
traits of neuroticism and openness than participants who were satisfied with their weight. Participants who were satisfied with their weight were more likely to have personality traits of extroversion, conscientiousness and agreeableness than participants with weight dissatisfaction. The secondary hypotheses were that 1) participants with weight dissatisfaction would spend more time in moderate to vigorous activity exercise than those who were weight satisfied, 2) participants with weight dissatisfaction would have a higher fruit and vegetable intake than those who were weight satisfied, and 3) personality traits, fruit and vegetable intake and exercise would be significant predictors of weight dissatisfaction. The exploratory hypothesis was that overweight and obese individuals were more likely to have an accurate perception of weight status than to normal weight individuals.

\subsection{Participants and Recruitment:}

Participants were recruited from eight different universities: University of Rhode Island, Kansas State University, Syracuse University, South Dakota University, University of Florida, University of Maine, University of Tennessee and West Virginia University. Participants were recruited in select classes, such as psychology and nutrition, those who completed the survey received extra credit. The requirements to participate in the CEBPS study were: being 18 years or older, being enrolled in college courses at one of the participating university, and having access to the internet.

Participants' age range was restricted to 18 through 24 to be consistent with other research $(17,18,22,35)$ and those with a BMI of less than or equal to 18.5 $\mathrm{kg} / \mathrm{m}^{2}$ were excluded to limit the possibility of including participants with serious weight-related pathology such as active anorexia nervosa or cancer. The analytic 
sample for this study included participants who answered operational weight dissatisfaction questions on the survey $(n=1,838)$. The sample size of participants with valid data about personality traits $(n=1,051)$, fruit and vegetable intake $(n=1,783)$ and physical activity $(n=1,779)$ varied. The CEBPS survey received IRB approval from each of the different institutions and all participants indicated informed consent for their data to be used for research. All data were de-identified prior to data analysis. The study was approved at the University of Rhode Island Institutional Review Board.

\subsection{Measures:}

CEBPS was a 100-item online survey, which took around 25 minutes to complete where a majority of items used a 5-point Likert scale $(1=$ strongly agree, $2=$ agree, $3=$ neutral, $4=$ disagree, $5=$ strongly disagree). Three items assessed weight dissatisfaction and dependent variables were assessed using validated instruments; Neuroticism, Extraversion, Openness to Experience Personality Inventory, NEO-PI-R, International Physical Activity Questionnaire, IPAQ, and the National Cancer Institute Fruit and Vegetable Screener, NCI FVS, $(66,67)$.

\subsection{Variables:}

Weight Dissatisfaction:

Weight dissatisfaction was defined using two different criteria, an operational definition and an affective definition. Separate analyses were conducted using the operational and affective weight dissatisfaction variables and all analyses were conducted separately for college males and females. 
Operational weight dissatisfaction was defined as a combination of two variables using the methodology of Jaworowska et al., (36) and Gunnare et al., (17). The first item assessed participants' perception toward their body weight: "How do you describe your weight?" The responses included: (1) Very underweight, (2) Slightly underweight, (3) About the right weight, (4) Slightly overweight, (5) Very overweight (6) Choose not to answer. The second item assessed valence of dissatisfaction defined as actively trying to change weight: "Which of the following are you trying to do about your weight?" Response categories include (1) Lose weight, (2) Gain weight, (3) Stay the same weight, (4) I am not trying to do anything about my weight, and (5) Choose not to answer. The response for these two items were combined to create the weight dissatisfaction variable. Participants were classified as operationally weight dissatisfied if they reported that they wanted to "Lose Weight" or "Gain Weight" and categorized themselves as "Slightly underweight" "About the right weight" and "Slightly overweight". Participants were classified as weight satisfied of they wanted to "Stay the same" and "Not trying" and categorize themselves as "Slightly underweight" "About the right weight" and "Slightly overweight". "Choose not to answer" $(\mathrm{n}=24)$, "Very underweight" $(\mathrm{n}=11)$ and "Very overweight" $(\mathrm{n}=79)$ were scored as missing, these participants were not included in analyses using the operational definition. Very underweight and very overweight were excluded from the analysis to avoid distorting the results by including the $5 \%$ of the sample with the most extreme values.

Weight dissatisfaction was also assessed by the affective perception of body weight: "How do you feel about your current weight?" The responses include: (1) "I 
am happy with my current weight", (2) "I don't care about my current weight”, (3) "I am upset about my current weight", and (4) "Choose not to answer". Participants who responded "I am upset about my current weight" were classified as affective weight dissatisfied. Participants with responses "I am happy with my current weight and, "I don't care about my current weight" were classified as affective weight satisfied. "Choose not to answer" was scored as missing, these participants were excluded from affective analyses. Only two universities, University of Rhode Island and West Virginia University assessed affective weight dissatisfaction thus the sample size for these analyses is reduced $(n=790)$.

Additional variables and different models of weight dissatisfaction were used in exploratory analyses to investigate the relationship between weight dissatisfaction and outcome variables. Exploratory models combined the operational and affective definitions. Additional weight dissatisfaction related variable was based on the items: "What is your current weight? With a fill in response "__ pounds" and "What weight would you like to be?” with a fill in-in response “___pounds.” Quantitative weight dissatisfaction was calculated as the absolute value of "like weight" - "current weight" (35). All universities assessed the quantitative weight dissatisfaction variable, however the sample size is reduced, because a limited number of participants completed valid fill-in responses to the questions $(n=789)$.

\section{Ten-Item Personality Inventory (Big Five Inventory):}

Participants' dominant personality trait was determined using the NEO personality inventory (66). Participants answered the ten-item personality inventory by choosing 1-8: (1) Disagree strongly, (2) Disagree moderately, (3) Disagree a little, (4) 
Neither agree nor disagree (5) Agree a little, (6) Agree moderately, (7) Agree strongly, (8) Choose not to answer to the ten personality traits listed as: (1) Extroverted, enthusiastic, (2) Critical, quarrelsome, (3) Dependable, self- disciplined, (4) Anxious, easily upset, (5) Open to new experiences, complex, (6) Reserved, quiet, (7) Sympathetic, warm, (8) Disorganized, careless, (9) Calm, emotionally, stable and (10) conventional, uncreative.

Based on the scoring methodology of Gosling et al., each personality trait is determined by 2 answers from the inventory (39). The personality trait extroversion included (1) extroverted, enthusiastic and the reverse of (6) reserved, quiet. The personality trait agreeableness included: (7) sympathetic, warm and the reverse of (2) critical, quarrelsome. Conscientiousness included: (3) dependable, self-disciplined and the reverse of (8) disorganized, careless. Neuroticism included: (9) calm, emotionally; stable and the reverse of (4) anxious, easily upset. Openness to experiences included: (5) open to new experiences, complex and the reverse of (10) conventional, uncreative. The reversed items were recoded (response categories (1-7) were subtracted from 8). The two items from each personality trait were averaged, (added and divided by 2) (39). The trait with the highest score was defined as the participants' dominant personality trait following the methodology of Goslin et al. (39). If a participant scored the same numerical value for more than one personality traits, they were defined as having no dominant trait and were excluded from the primary analyses but included in the secondary regression analysis with those having more than one dominant trait coded as a combined trait. 
International Physical Activity Questionnaire:

The International Physical Activity Questionnaire (IPAQ) is a validated instrument to assess physical activity for adults between the ages of 18-65 years (11, $68,69)$. IPAQ is a 7-item, self-administered survey, which measured the frequency (measured in days per week), duration (minutes per day) and intensity of the physical activity (68). The three levels intensity measured were: walking, moderate activity, and vigorous physical activity (68). Activity levels were reported as minutes/week. This study used moderate and vigorous activity, which was calculated as the sum of moderate + vigorous minutes/week. On the CEBPS survey, the IPAQ was pretruncated meaning the highest physical activity minutes a day was 180 minutes (68).

\section{National Cancer Institute Fruit and Vegetable Screener (NCI FVS):}

The National Cancer Institute (NCI) Fruit and Vegetable Screener (FVS) measures fruit and vegetable intake as frequency of consumption over the last month and quantity of consumption over the last month (12). The FVS included items measuring 9 categories of fruits and vegetables: $100 \%$ juice, fruit, lettuce salad, French fries/fried potatoes, other white potatoes, cooked dried beans, other vegetables, tomato sauce and vegetable soups. For example, the measure asked: Over the last month, how often did you eat tomato sauce? Include tomato sauce on pasta or macaroni, rice, pizza and other dishes. The responses included: (1) Never, (2) 1-3 times last month, (3) 1-2 times per week, (4) 3-4 times per week, (5) 5-6 times per week, (6) 1 time per day, (7) 2 times per day, (8) 3 times per day, (9) 4 times per day, (10) 5 or more times per day, (11) Choose not to answer. Quantity of participants' fruits and vegetables consumption was assessed with 4 response categories, e.g., 
"Each time you ate lettuce salad, how much did you usually eat? (1) Did not eat lettuce salad, (2) About $1 \frac{1}{2}$ cup, (3) About 1 cup, (4) About 2 cups, (5) More than 2 cups, (6) Choose not to answer. The NCI fruit and vegetable screener was scored using the scoring algorithm of frequency multiplied by quantity calculated as cups per day following NCI methods (67).

\section{Weight Perception}

To determine if a participant's weight perception was accurate, participants' weight status was compared to their weight description. Weight status was determined from participants' self-reported weight and self-reported height. BMI was calculated by dividing body weight (in $\mathrm{kg}$ ) by height (in meters squared), it was then compared to the response from the item: How do you describe your weight? The responses included: (1) Very underweight, (2) Slightly underweight, (3) About the right weight, (4) Slightly overweight, (5) Very overweight (6) Choose not to answer. For these analyses "Choose not to answer" was coded as missing and these subjects were excluded from these analyses. Participants with missing height or weight were also excluded.

Following the World Health Organization (WHO), (70) a BMI between 18.6$24.9 \mathrm{~kg} / \mathrm{m}^{2}$ is defined as "normal weight". Normal weight participants who defined their weight as "About right" were defined as "accurate", all other responses were defined as "not accurate." BMI between $25.0-29.9 \mathrm{~kg} / \mathrm{m}^{2}$ is defined as overweight. Overweight participants choosing the response "Slightly overweight" were defined as "accurate" with other responses defined as "not accurate." A BMI over $30 \mathrm{~kg} / \mathrm{m}^{2}$ is 
defined as "obese." Obese participants were defined as accurate if they chose the response, "very overweight" with other responses being coded as "not accurate".

\subsection{Demographics}

Students' self-reported gender (male, female, transgender, gender queer, different identify), age $(18,19,20,21,22,23,24)$, race (white, black, Asian, native Hawaiian, American Indian), and year in school (freshman, sophomore, junior, senior, graduate). For purposes of analysis, gender male and gender female were used to define gender with other gender identities excluded $(<1 \%, n=16)$. Participants were also categorized by geographic location dependent on university location (University of Rhode Island, Kansas State University, Syracuse University, South Dakota University, University of Florida, University of Maine, University of Tennessee and West Virginia University).

\subsection{Data Analyses and Statistics}

All data analysis was conducted using SPSS version 22.0. For demographic variables (age, race, gender, ethnicity), dependent and independent variables, descriptive statistics were analyzed using frequencies, means, standard deviations, and ranges. Outliers greater than four standard deviations from the mean were excluded in all continuous variables (71). After exclusions, normalcy was determined for continuous variables. Two variables did not meet criteria for normalcy (72); see Appendix B for values. Physical activity variables were transformed using the 
logarithmic transformation (69) and fruits and vegetable were transformed using the square root transformation (73).

Primary, secondary and exploratory hypotheses were assessed separately by gender. In addition, analyses were conducted separately by operational and affective definitions. Weight dissatisfaction was defined as a binary variable (dissatisfied or satisfied) following the methods described in variables. The primary hypothesis was assessed by $\mathrm{X}^{2}$ analysis comparing weight dissatisfaction to the five dominant personality types. Independent t-tests were used to assess secondary hypotheses (fruit and vegetable intake and minutes of moderate and vigorous physical activity) comparing weight dissatisfaction group by dependent variables. Logistic regression was utilized to predict weight dissatisfaction using personality type (6 types; more than one dominant type coded as combined), physical activity, and fruit and vegetable intake. To examine determine the effect of weight status on accuracy of perception $\mathrm{X}^{2}$ analysis was utilized (overweight and obese/normal weight and accurate/not accurate). 


\section{CHAPTER 4 \\ Results}

\subsection{Demographics}

Population sample characteristics are displayed in Table 1. The sample $(\mathrm{n}=1,838)$ was predominately Caucasian $(89 \%, \mathrm{n}=1,654)$ and female $(72 \%, \mathrm{n}=1,400)$, with a mean age of $19.57( \pm 1.406)$ years. The majority of participants were college freshmen $(42 \%, \mathrm{n}=784)$. Participants had an average BMI in the healthy range (Mean$23.5 \pm 3.9) ; 31 \%$ of participants were categorized as overweight or obese.

\subsection{Primary Outcome: Personality Traits and Weight Dissatisfaction}

More than half of males $(60 \%, \mathrm{n}=308)$ and females $(63 \%, \mathrm{n}=831)$ were categorized as being operationally weight dissatisfied, using the two questions: "What do you want to do about your weight?" and "How would you describe your weight?", as shown in Table 2; those participants $(6 \%, \mathrm{n}=119)$ that did not answer the two questions used for the operational weight dissatisfaction variable and participants with no dominant personality trait $(\mathrm{n}=712)$ as well as participants who self-categorized as very underweight or very overweight were excluded from these analyses. The affective weight dissatisfaction variable is shown in Table 2. Males (19\%, n=52) and females $(42 \%, \mathrm{n}=214)$ were categorized as weight dissatisfied using the affective item: “How do you feel about you weight?" Participants $(58 \%, \mathrm{n}=1,184)$ who did not answer this question or who answered, "Choose not to answer" were excluded from these analyses. There was no statistically significant association between operational weight dissatisfaction and personality trait in males $\left(X^{2}(4) \mathrm{n}=288=7.0, p=.14\right)$ or females $\left(X^{2}(4), \mathrm{n}=782=1.8, p=.78\right)$ as shown in Table 3. Similarly, there were no significant differences for affective weight dissatisfaction and personality trait in 
males $\left(X^{2}(4) \mathrm{n}=172=2.3, p=.67\right)$ or females $\left(X^{2}(4), \mathrm{n}=410=4.9, p=.30\right)$ as shown in

\section{Table 4.}

\subsection{Secondary Outcome: Physical Activity, Fruit and Vegetable Intake and Weight}

\section{Dissatisfaction}

No association was found between operational weight dissatisfaction and minutes of moderate and vigorous physical activity in males $(t=0.27, p=0.78)$ or females $(\mathrm{t}=0.86, p=0.39)$ as displayed in Table 5. Affective weight dissatisfaction was associated with physical activity in males $(t=2.6, p=0.01)$, but not females $(t=$ $0.77, p=0.44$ ) as displayed in Table 5. Only a minority of participants reported completing less than the recommended amount of exercise. The proportion completing less than recommendations for operationally weight dissatisfied college males was $13 \%$, for females was $24 \%$ and affectively weight dissatisfied males was $6 \%$ and females was $19 \%$. Similarly, the proportion of weight satisfied males completing less than recommendations was $9 \%$ by operational and $11 \%$ affective definitions and the proportion of females was $16 \%$ by operational and $19 \%$ affective definitions.

No association was found between operational weight dissatisfaction and fruit and vegetable intake in males $(t=0.76, p=0.45)$ and females $(t=0.10, p=0.92)$ as shown in Table 6. No association was found between affective weight dissatisfaction and fruit and vegetable intake in males $(t=0.02, p=0.99)$ or females $(t=1.41 p=0.16)$ as shown in Table 6. The proportion completing less than recommendations for weight dissatisfied college males was $50 \%$, for females was $48 \%$ and affectively weight dissatisfied males was $86 \%$ and females was $68 \%$. Similarly, the proportion of weight satisfied males completing less than recommendations was $70 \%$ by operational 
and $49 \%$ affective definitions and the proportion of females was $69 \%$ by operational and $69 \%$ affective definitions.

Logistic regression models were constructed to determine if the three covariates (dominant personality traits, physical activity and fruit and vegetable intake) predicted weight dissatisfaction separate models for males and females. Logistic regression analysis revealed no statistical significance between the covariates and operational weight dissatisfaction variable for males $\left(x^{2}(7)=3.71, \mathrm{p}=0.81, \mathrm{R}^{2}\right.$ value $=0.01)$ or females $\left(x^{2}(7)=5.44, p=0.71, \mathrm{R}^{2}\right.$ value $\left.=.01\right)$ as shown in Table 7.

Logistic regression analysis revealed differences between the covariates and affective weight dissatisfaction variable for college males $\left(x^{2}(7)=19.59, \mathrm{p}=0.01, \mathrm{R}^{2}\right.$ value $=0.07)$ confirming the univariate results that weight satisfied males were more active; no other variables were significant. There was no difference for the affective weight dissatisfaction variable for college females $\left(x^{2}(7)=7.72, \mathrm{p}=0.41, \mathrm{R}^{2}\right.$ value $=$ 0.02) as displayed in Table 7.

\subsection{Exploratory Outcomes}

\section{Exploratory Outcome: Perception of Weight Status}

Males $(31 \%, n=141)$ and females $(36 \%, n=460)$ were categorized as overweight/obese based on BMI calculations using self-reported height and weight see Table 8 . There were significant differences in proportion accurately perceiving their weight for both males and females $\left(x^{2}=94.97, \mathrm{p}<0.01\right)$ and females $\left(x^{2}=334.42\right.$, $\mathrm{p}<0.01)$. Most males $(88 \%)$ who were overweight or obese accurately perceived their weight as "Slightly Overweight" and "Overweight" and 70\% of those who were normal weight accurately perceived their weight as "slightly underweight" or "about 
the right weight". However more females who were normal weight were accurate in their perception $(88 \%)$ than females who were overweight or obese $(68 \%)$. as shown in Table 9. Participants with a BMI $<18.5 \mathrm{~kg} / \mathrm{m}^{2}$ were excluded.

Exploratory Outcome: Quantification of Desired Weight Change

The majority of males and females with valid responses to the weight item did not want to change their weight; only $36 \%$ males $(n=194)$ and $42 \%$ females $(n=592)$ wanting to change their weight. College females who wanted to change their weight generally wanted to lose weight (Mean= -9.5 pounds, $\mathrm{SD}=14.34)$. College males who wanted to change weight either wanted to lose weight (Mean=3.73, $\mathrm{SD}=11.56$ ) or gain weight $($ Mean=9.92, $\mathrm{SD}=12.33)$. Using the operational definition, both dissatisfied males and females wanted to change a greater amount of weight than satisfied males $(\mathrm{t}=6.83, p<0.05)$ and females $(\mathrm{t}=12.32, p<0.05)$. Using the affective definition, there was no relationship between weight dissatisfaction and amount of weight change for either males $(\mathrm{t}=-0.84, p=0.43)$ or females $(\mathrm{t}=-2.16, p=0.05)$. Exploratory Outcome: Weight Dissatisfaction Variables

The operational and affective definitions were compared in Table 10. There were significant differences between operational and affective weight dissatisfaction variables for males $\left(x^{2}=25.53, \mathrm{p}<0.05\right)$ and females $\left(x^{2}=133.09, \mathrm{p}<0.05\right)$. Although almost all (95\%) of males who were weight satisfied were satisfied according to both conditions, only $33 \%$ of those who were weight dissatisfied were dissatisfied according to both definitions. In contrast, $90 \%$ of females who were weight dissatisfied were dissatisfied by both definitions but only $53 \%$ of those who were satisfied were classified as satisfied by both definitions. 


\section{CHAPTER 5}

\section{Discussion}

The purpose of this study was to gain a better understanding of the associations between personality traits, fruit and vegetable intake, physical activity and weight dissatisfaction in college students after controlling for gender $(14,24,26,34)$. This study was a continuation of the research of Palmers who explored the relationship between weight dissatisfaction and weight change in college students (35). Even though there was no association between weight dissatisfaction and weight change over time, due to the prevalence and consequences of weight dissatisfaction in this population it is important to continue this line of research (35). Findings from this study also support previous research that has found weight dissatisfaction is present in both males and females in college, but males vary between wishing to gain or lose weight depending on current weight while most females wish to lose weight $(17,25$, $26,34,74)$. However, no significant relationship was found between weight dissatisfaction and personality traits, physical activity and fruit and vegetable intake in males and females using the operational and affective definitions with the exception that males differed in physical activity using the affective definition. The combination of the two definitions, operational and affective was explored, but the majority of females and 2/5 of males were classified differently by the two definitions. In addition, the affective item was only included in the surveys at two of the eight participating institutions, which limited the sample.

Overall, $34 \%$ of our sample was either overweight or obese. These findings are similar to the 2016 American College Health Association National College Health 
Assessment (ACH-ANCHA), which found 36.8\% of college students were overweight or obese (27). A possible selection bias could have also occurred, since the survey was only given to students in select nutrition and psychology courses.

The operational weight dissatisfaction variable used in this study was similar to the dissatisfaction variable used in Jaworowska et al., (36). Jaworowska et al., (36) asked how participants perceived their weight and if they were trying to lose weight. Based off of those two questions, Jaworowska et al., (36) defined 37\% of males and $68 \%$ of females as weight dissatisfied. Using the operational definition, we found $63 \%$ of college females and $60 \%$ of college males were classified as weight dissatisfied. Our results for operational weight dissatisfaction were similar for college females, however they are not similar for college males. The affective weight dissatisfaction variable used in this study was similar to Gunnare et al., (17) and Palmer (35) asking participants, "How do you feel about your current weight?". Gunnare et al., asked participants "How satisfied are you with your current body?" They found 35\% of males and $46 \%$ of females were dissatisfied. Palmer (35) found 25\% of college males and 54\% of college females to be weight dissatisfied. Palmers' proportion of weight dissatisfied participants included both quantitative and affective definitions. Although the males were similar to current study findings (22\%), most (77\%) of females in the current study were dissatisfied. It appears that females perceive how they feel and how satisfied they are with their weight differently. Future research is needed to explore the affective definition.

College males (46\%) and females (38\%) with a BMI of overweight/obese were weight dissatisfied. These results were not consistent with previous research on body 
and weight dissatisfaction. Previous research shows majority of college students with a BMI over $25 \mathrm{~kg} / \mathrm{m}^{2}$ were weight or body dissatisfied $(17,18,20,23)$. Weight dissatisfaction is found in normal, overweight and obese college students. These findings are consistent with previous research, which reveal misperceptions regarding actual body weight and size, as well as a drive for thinness in females and an increase desire for muscularity in males (24-26).

Consistent with previous research $(36,37)$, quantification of desired weight change revealed that females on average desire to lose 9.5 pounds which is $6.5 \%$ of their body weight, while males displayed mixed results with both a desire to lose and gain an average of 3.73 pounds. Although all universities asked the questions for the quantification weight dissatisfaction variable, however only 786 participants answered the question with valid write in responses. The gender differences between males and females and weight dissatisfaction are complex, since males that are normal weight tend to want to gain or lose weight, while women, regardless of BMI, generally want to lose weight $(17,21,24,30,34)$.

This study assessed personality traits based on the NEO ten-item personality inventory (39). There was no association between weight dissatisfaction and personality traits. To our knowledge, no previous research has been conducted with weight dissatisfaction and personality traits. However, previous research has been conducted with body dissatisfaction, weight status and personality traits using a fiftyitem personality inventory $(6,43)$. For our study there may not have been a relationship observed because $37 \%$ of participants did not have a single dominant personality trait using the ten-item inventory thus were excluded from this analysis. 
Although the lack of association was confirmed by regression analyses where those with more than one trait were added as a group and included in the analysis, this approach has limitations because all combinations were included in one group. Future studies should consider using a more sensitive questionnaire; if a fifty to one hundred and twenty-item inventory were used there would be a better likelihood to determine the participants' dominant personality trait $(43,75)$.

There was no difference by objective weight dissatisfaction for physical activity and fruit and vegetable intake for either college males or females. However, college males differed by affective weight dissatisfaction in minutes of moderate and vigorous physical activity with weight satisfied males exercising more than those who were weight dissatisfied. These findings were not consistent with previous research regarding physical activity and fruit and vegetable intake $(5,6,16,57)$. Previous research has found college students who are weight dissatisfied tend to consume a higher proportion of fruits and vegetables $(16,57)$. Previous research has found weight dissatisfied college females demonstrate an excessive desire to exercise (6) and weight dissatisfied college males tend to increase the amount of physical activity (5). A difference could have occurred between previous research and this study because participants might have under reported their physical activity levels and fruit and vegetable intake.

This study found college males (26\%) and females (45\%) who were weight dissatisfied were doing less than the recommended amount of physical activity per week. However, this study found a similar proportion of weight satisfied males (31\%) and females (22\%) were not meeting the physical activity recommendations. Previous 
research regarding physical activity recommendations and the total college student population (ACH-NCHA, 2016), (27) report of $49 \%$ of college males and $54 \%$ of college females are not meeting the physical activity guidelines. This sample was not consistent with previous research, because a majority of the college males (77\%) who did meet physical activity recommendations.

We also found most college males (84\%) and females $(83 \%)$ reported eating less than the recommended five cups of fruit and vegetables per day regardless of weight satisfaction status. The proportion completing less than recommendations for weight dissatisfied college males was $50 \%$, for females was $48 \%$ and affectively weight dissatisfied males was $86 \%$ and females was $68 \%$. Similarly, the proportion of weight satisfied males completing less than recommendations was $70 \%$ by operational and $49 \%$ affective definitions and the proportion of females was $69 \%$ by operational and $69 \%$ affective definitions. These findings are consistent previous research (16, 57), and the ACH-NCHA, 2016, (27), which reported $95 \%$ of college males and $94 \%$ of college females consumed less than the recommended amount of five cups of fruit and vegetables a day.

In general, there was no difference between personality traits, physical activity, fruit and vegetable intake and weight dissatisfaction. Nevertheless, these results could still be helpful in the development of health related activities for college students. Both college males and females with low levels of physical activity and a low intake of fruits and vegetables are at increased risk of weight gain throughout college, which can increase risk for chronic diseases later in life $(18,21-23,76)$. Future research determining the dominant personality traits associated with weight dissatisfaction 
could also lead to targeted interventions to decrease risky behavior to change weight in the college population $(5-7,24,33)$.

There were several limitations to this study. This secondary data analysis used a self-reported online survey. In-person interviews might have provided different results. The CEBPS survey was long; participants could have experienced fatigue while completing the survey. Reliability of self-reported height and weight was a limitation in this study. Body dissatisfaction was not assessed, although weight dissatisfaction was assessed using both the operational and affective definitions. During all analyses gender was controlled for, however there were fewer males $(n=$ $510)$ in this study, compared to females $(n=1,328)$. Another limitation was the scoring algorithm of personality traits; $712(37 \%)$ of participants were excluded from personality analyses because they had two or more dominant traits. In addition, the affective weight dissatisfaction item was only included in surveys at two institutions $(n=859,42 \%)$.

Despite limitations, this study had several strengths. This study included validated instruments to assess personality (NEO), activity level (IPQA) and fruit and vegetable intake (NCI FVS). Participants were from multiple geographic locations, representing eight states throughout the study. This combined, with a large sample size $(n=1,838)$ was also a strength to this study, because it increases generalizability to the college population.

\section{Conclusion \& Application:}

Weight dissatisfaction was not related to personality traits, physical activity or fruit and vegetable consumption in college students. However, further research should 
continue to examine weight dissatisfaction among college students due to the high number $(\mathrm{n}=1,188,62 \%)$ of college students we have found in this study who were operationally weight dissatisfaction and the differences in weight dissatisfaction between college males and college females. Although this study found no relationship, it highlighted the key question for future research: what are the drivers of weight gain in college students and how does this relate to weight satisfaction? Additional future questions for research include: what is the association between personality traits and maladaptive behaviors, why does moderate to vigorous activity decrease in college students, and why is fruit and vegetable intake so low in college students?" In conclusion, future research needs to keep exploring and looking at different measures of weight dissatisfaction to assess drivers of weight and behavior change in college students and whether these differ by personality traits. 
Tables:

Table 1: Participants' Demographic Characteristics $(\mathrm{n}=1,838)$.

\begin{tabular}{|c|c|c|c|}
\hline & & Mean & SD \\
\hline \multirow[t]{2}{*}{ Age } & & 19.57 & 1.40 \\
\hline & & $\mathbf{n}$ & $\%$ \\
\hline \multicolumn{4}{|l|}{ Gender } \\
\hline & Male & 510 & 28 \\
\hline & Female & 1,328 & 72 \\
\hline \multicolumn{4}{|l|}{ Ethnicity } \\
\hline & Caucasian & 1,577 & 86 \\
\hline & African American & 75 & 4 \\
\hline & Asian & 89 & 5 \\
\hline & Native Hawaiian & 7 & 1 \\
\hline & American Indian & 10 & 1 \\
\hline & $\begin{array}{l}\text { Chose not to } \\
\text { answer }\end{array}$ & 8 & 1 \\
\hline \multicolumn{4}{|l|}{ School Year } \\
\hline & Freshman & 744 & 41 \\
\hline & Sophomore & 422 & 23 \\
\hline & Junior & 332 & 18 \\
\hline & Senior & 271 & 15 \\
\hline \multicolumn{4}{|l|}{$\begin{array}{c}\text { University } \\
\text { Location }\end{array}$} \\
\hline & Alabama & 11 & 1 \\
\hline & Florida & 11 & 1 \\
\hline & Maine & 122 & 7 \\
\hline & Kansas & 196 & 11 \\
\hline & New York & 212 & 12 \\
\hline & Tennessee & 320 & 17 \\
\hline & South Dakota & 92 & 5 \\
\hline & West Virginia & 169 & 9 \\
\hline & Rhode Island & 713 & 38 \\
\hline
\end{tabular}


Table 2: Proportion by Perceived Body Weight Category by Operational Weight Dissatisfaction and Satisfaction by Gender $(n=1,831)$.

\begin{tabular}{|c|c|c|c|}
\hline \multirow[t]{2}{*}{$\begin{array}{l}\text { Males, } \\
\text { Weight Dissatisfied }^{1}\end{array}$} & \multirow[t]{2}{*}{$\mathbf{n}$} & $\begin{array}{c}\text { Lose } \\
\text { Weight }\end{array}$ & $\begin{array}{c}\text { Gain } \\
\text { Weight }\end{array}$ \\
\hline & & $\%$ & $\%$ \\
\hline Slightly underweight & 56 & 0 & 10 \\
\hline About the right weight & 154 & 9 & 20 \\
\hline Slightly overweight & 93 & 17 & 0 \\
\hline \multicolumn{4}{|l|}{$\begin{array}{l}\text { Females, } \\
\text { Weight Dissatisfied }^{1}\end{array}$} \\
\hline Slightly underweight & 26 & 1 & 1 \\
\hline About the right weight & 424 & 30 & 1 \\
\hline Slightly overweight & 379 & 27 & 0 \\
\hline \multirow{2}{*}{$\begin{array}{l}\text { Males, } \\
\text { Weight Satisfied }^{2}\end{array}$} & $\mathbf{n}$ & $\begin{array}{c}\text { Stay } \\
\text { Same }\end{array}$ & $\begin{array}{c}\text { Not } \\
\text { Trying }\end{array}$ \\
\hline & & $\%$ & $\%$ \\
\hline Slightly underweight & 13 & 1 & 1 \\
\hline About the right weight & 169 & 24 & 8 \\
\hline Slightly overweight & 20 & 2 & 2 \\
\hline \multicolumn{4}{|l|}{$\begin{array}{l}\text { Females, } \\
\text { Weight Satisfied }^{2}\end{array}$} \\
\hline Slightly underweight & 40 & 2 & 1 \\
\hline About the right weight & 421 & 23 & 7 \\
\hline Slightly overweight & 36 & 1 & 1 \\
\hline
\end{tabular}

${ }^{1}$ Which are you trying to do about your weight? Responses: Lose or gain weight were classified as weight dissatisfied.

${ }^{2}$ Which are you trying to do about your weight? Responses: Stay the same or not change were classified as weight satisfied. 
Table 3: Affective Weight Dissatisfaction and Satisfaction by Gender $(n=790)^{3}$.

\begin{tabular}{|l|c|c|}
\hline Males & n & $\%$ \\
\hline Weight Dissatisfied & 52 & 18.5 \\
\hline Weight Satisfied & 229 & 81.5 \\
\hline Females & 214 & 42 \\
\hline Weight Dissatisfied & 295 & 58 \\
\hline Weight Satisfied &
\end{tabular}

${ }^{3}$ How do you feel about your current weight? Responses: I am happy with my current weight and I don't care about my current weight classified as weight satisfied. Response: I am upset about my current weight classified as weight dissatisfied. 
Table 4: Weight Dissatisfaction and Personality Traits by Gender

\begin{tabular}{|c|c|c|c|c|c|}
\hline \multirow[t]{2}{*}{ Males, Operational } & $\mathbf{n}$ & $\begin{array}{c}\text { Weight } \\
\text { Dissatisfied }^{1}\end{array}$ & $\begin{array}{c}\text { Weight } \\
\text { Satisfied }^{2}\end{array}$ & $\mathbf{x}^{2}$ & $p$ \\
\hline & & $\%$ & $\%$ & & \\
\hline Extrovert & 36 & 75 & 25 & \multirow{5}{*}{6.96} & \multirow{5}{*}{0.14} \\
\hline Agreeableness & 24 & 50 & 50 & & \\
\hline Conscientiousness & 117 & 58 & 42 & & \\
\hline Neuroticism & 49 & 49 & 51 & & \\
\hline Openness & 68 & 60 & 40 & & \\
\hline \multicolumn{6}{|l|}{ Females, Operational } \\
\hline Extrovert & 90 & 62 & 38 & \multirow{5}{*}{1.76} & \multirow{5}{*}{0.78} \\
\hline Agreeableness & 116 & 57 & 43 & & \\
\hline Conscientiousness & 379 & 63 & 37 & & \\
\hline Neuroticism & 59 & 58 & 42 & & \\
\hline Openness & 157 & 62 & 38 & & \\
\hline \multirow[t]{2}{*}{ Males, Affective ${ }^{3}$} & $\mathbf{n}$ & $\begin{array}{c}\text { Weight } \\
\text { Dissatisfied }\end{array}$ & $\begin{array}{c}\text { Weight } \\
\text { Satisfied }\end{array}$ & $\mathrm{x}^{2}$ & $p$ \\
\hline & & $\%$ & $\%$ & & \\
\hline Extrovert & 21 & 23 & 77 & \multirow{5}{*}{2.34} & \multirow{5}{*}{0.67} \\
\hline Agreeableness & 11 & 8 & 92 & & \\
\hline Conscientiousness & 71 & 18 & 82 & & \\
\hline Neuroticism & 28 & 27 & 73 & & \\
\hline Openness & 41 & 21 & 79 & & \\
\hline \multicolumn{6}{|l|}{ Females, Affective ${ }^{3}$} \\
\hline Extrovert & 45 & 59 & 41 & \multirow{5}{*}{4.86} & \multirow{5}{*}{0.30} \\
\hline Agreeableness & 33 & 41 & 59 & & \\
\hline Conscientiousness & 149 & 43 & 57 & & \\
\hline Neuroticism & 29 & 32 & 68 & & \\
\hline Openness & 154 & 42 & 58 & & \\
\hline
\end{tabular}

${ }^{1}$ Which are you trying to do about your weight? Responses: Lose or gain weight were classified as weight dissatisfied.

${ }^{2}$ Which are you trying to do about your weight? Responses: Stay the same or not change were classified as weight satisfied.

${ }^{3}$ How do you feel about your current weight? Responses: I am happy with my current weight and I don't care about my current weight classified as weight satisfied.

Response: I am upset about my current weight classified as weight dissatisfied. 
Table 5: Weight Dissatisfaction and Physical Activity (Minutes Moderate and Vigorous per Week) by Gender

\begin{tabular}{|c|c|c|c|c|c|}
\hline Males, Operational & $\mathbf{n}$ & Mean & SD & $\mathbf{t}$ & Sig. \\
\hline Weight Dissatisfied $^{1}$ & 293 & 419.42 & 338.5 & \multirow[t]{2}{*}{-0.27} & \multirow[t]{2}{*}{0.78} \\
\hline Weight Satisfied $^{2}$ & 197 & 436.24 & 407.13 & & \\
\hline \multicolumn{6}{|l|}{ Females, Operational } \\
\hline Weight Dissatisfied $^{1}$ & 807 & 266.89 & 282.56 & \multirow[t]{2}{*}{-0.86} & \multirow[t]{2}{*}{0.39} \\
\hline Weight Satisfied $^{2}$ & 482 & 250.45 & 255.12 & & \\
\hline \multicolumn{6}{|l|}{ Males, Affective ${ }^{3}$} \\
\hline Weight Dissatisfied & 50 & 343.60 & 298.53 & \multirow[t]{2}{*}{2.56} & \multirow[t]{2}{*}{$0.01 *$} \\
\hline Weight Satisfied & 222 & 541.26 & 420.73 & & \\
\hline \multicolumn{6}{|l|}{ Females, Affective ${ }^{3}$} \\
\hline Weight Dissatisfied & 211 & 283.60 & 283.80 & \multirow[t]{2}{*}{0.77} & \multirow[t]{2}{*}{0.44} \\
\hline Weight Satisfied & 293 & 308.53 & 319.00 & & \\
\hline
\end{tabular}

${ }^{1}$ Which are you trying to do about your weight? Responses: Lose or gain weight were classified as weight dissatisfied.

${ }^{2}$ Which are you trying to do about your weight? Responses: Stay the same or not change were classified as weight satisfied.

${ }^{3}$ How do you feel about your current weight? Responses: I am happy with my current weight and I don't care about my current weight classified as weight satisfied.

Response: I am upset about my current weight classified as weight dissatisfied. 
Table 6: Weight Dissatisfaction and Fruit and Vegetable Intake (Cups/day) by Gender

\begin{tabular}{|c|c|c|c|c|c|}
\hline Males, Operational & $\mathbf{n}$ & Mean & SD & $\mathbf{t}$ & Sig. \\
\hline Weight Dissatisfied $^{1}$ & 297 & 3.32 & 3.07 & \multirow{2}{*}{0.76} & \multirow[b]{2}{*}{0.45} \\
\hline Weight Satisfied $^{2}$ & 195 & 3.52 & 2.86 & & \\
\hline \multicolumn{6}{|c|}{ Females, Operational } \\
\hline Weight Dissatisfied & 807 & 3.26 & 3.003 & \multirow[t]{2}{*}{-0.11} & \multirow[t]{2}{*}{0.92} \\
\hline Weight Satisfied & 484 & 3.19 & 2.60 & & \\
\hline Males, Affective ${ }^{3}$ & $\mathbf{n}$ & Mean & SD & $\mathbf{t}$ & Sig. \\
\hline Weight Dissatisfied & 51 & 3.33 & 2.89 & \multirow[b]{2}{*}{-0.02} & \multirow[b]{2}{*}{0.99} \\
\hline Weight Satisfied & 225 & 3.27 & 2.72 & & \\
\hline \multicolumn{6}{|l|}{ Females, Affective $^{3}$} \\
\hline Weight Dissatisfied & 211 & 3.30 & 2.62 & \multirow[b]{2}{*}{-1.41} & \multirow[b]{2}{*}{0.16} \\
\hline Weight Satisfied & 286 & 3.05 & 2.66 & & \\
\hline
\end{tabular}

${ }^{1}$ Which are you trying to do about your weight? Responses: Lose or gain weight were classified as weight dissatisfied.

${ }^{2}$ Which are you trying to do about your weight? Responses: Stay the same or not change were classified as weight satisfied.

${ }^{3}$ How do you feel about you current weight? Responses: I am happy with my current weight and I don't care about my current weight classified as weight satisfied.

Response: I am upset about my current weight classified as weight dissatisfied. 
Table 7: Weight Dissatisfaction and Personality Traits, Physical Activity and Fruit and Vegetable Intake Logistic Regression by Gender $(n=1,745)$.

\begin{tabular}{|c|c|c|c|c|c|}
\hline Males, Operational & B & S.E. & Sig & $\operatorname{Exp}(B)$ & CI \\
\hline \multicolumn{6}{|l|}{ Personality Traits } \\
\hline Extravert & -.77 & 1.02 & .45 & .46 & {$[.06,3.39]$} \\
\hline Agreeableness & .12 & .42 & .78 & 1.13 & {$[.50,2.54]$} \\
\hline Conscientiousness & .48 & .31 & .12 & 1.62 & {$[.88,3.00]$} \\
\hline Neuroticism & .33 & .43 & .44 & 1.39 & {$[.60,3.25]$} \\
\hline Openness & .20 & .29 & .49 & 1.23 & {$[.69,2.18]$} \\
\hline 2 or more personality traits & .21 & .29 & .48 & 1.23 & {$[.69,2.18]$} \\
\hline Physical Activity & -.02 & .06 & .65 & .97 & {$[.87,1.09]$} \\
\hline Fruit \& Vegetable Intake & .11 & .14 & .44 & 1.11 & {$[.85,1.45]$} \\
\hline \multicolumn{6}{|l|}{ Females, Operational } \\
\hline \multicolumn{6}{|l|}{ Personality Traits } \\
\hline Extravert & .02 & .24 & .93 & 1.02 & {$[.64,1.62]$} \\
\hline Agreeableness & .29 & .23 & .21 & 1.33 & {$[.85,2.09]$} \\
\hline Conscientiousness & .21 & .15 & .16 & 1.23 & {$[.92,1.64]$} \\
\hline Neuroticism & .05 & .27 & .85 & 1.05 & {$[.63,1.77]$} \\
\hline Openness & -.01 & .20 & .95 & .99 & {$[.66,1.47]$} \\
\hline 2 or more personality traits & -.06 & .30 & .83 & .94 & {$[.52,1.70]$} \\
\hline Physical Activity & .01 & .03 & .64 & 1.01 & {$[.96,1.08]$} \\
\hline Fruit \& Vegetable Intake & .01 & .09 & .92 & 1.01 & {$[.85 .1 .21]$} \\
\hline \multicolumn{6}{|l|}{ Males, Affective } \\
\hline \multicolumn{6}{|l|}{ Personality Traits } \\
\hline Extravert & -.68 & .69 & .33 & .51 & {$[.13,1.97]$} \\
\hline Agreeableness & -1.39 & .56 & .01 & .25 & {$[.08, .74]$} \\
\hline Conscientiousness & -.33 & .47 & .48 & .72 & {$[.29,1.80]$} \\
\hline Neuroticism & -.15 & .75 & .84 & .86 & {$[.20,3.72]$} \\
\hline Openness & -.66 & .54 & .22 & .52 & {$[.18,1.48]$} \\
\hline 2 or more personality traits & -.20 & .78 & .80 & .82 & {$[.18,3.81]$} \\
\hline Physical Activity & -.38 & .11 & $<.01 * *$ & .69 & {$[.56, .85]$} \\
\hline Fruit \& Vegetable Intake & .16 & .26 & .54 & 1.17 & {$[.71,1.93]$} \\
\hline \multicolumn{6}{|l|}{ Females, Affective } \\
\hline \multicolumn{6}{|l|}{ Personality Traits } \\
\hline Extravert & .17 & .39 & .67 & 1.18 & {$[.55,2.54]$} \\
\hline Agreeableness & .40 & .39 & .31 & 1.49 & {$[.69,3.2]$} \\
\hline Conscientiousness & .19 & .23 & .42 & 1.21 & {$[.77,1.89]$} \\
\hline Neuroticism & .23 & .42 & .58 & 1.26 & {$[.56,2.86]$} \\
\hline Openness & -.22 & .33 & .50 & .80 & {$[.42,1.53]$} \\
\hline 2 or more personality traits & .02 & .62 & .97 & 1.02 & {$[.30,3.45]$} \\
\hline Physical Activity & -.06 & .05 & .192 & .94 & {$[.86,1.03]$} \\
\hline Fruit \& Vegetable Intake & .25 & .15 & .09 & 1.28 & {$[.96,1.71]$} \\
\hline$*$ denotes $p<.05, * *$ denotes $\mathrm{p}<.01$ & & & & & \\
\hline
\end{tabular}


Table 8: Perception of Weight Status and BMI by Gender

\begin{tabular}{|c|c|c|c|c|}
\hline & Mean & SD & & \\
\hline \multirow[t]{2}{*}{$\overline{\text { BMI }}$} & 23.58 & 3.876 & & \\
\hline & $\mathbf{n}$ & $\%$ & & \\
\hline \multicolumn{3}{|l|}{ BMI Status } & & \\
\hline Normal weight & 1,101 & 68 & & \\
\hline Overweight & 455 & 28 & & \\
\hline Obese & 58 & 4 & & \\
\hline Males & $\mathbf{n}$ & BMI & BMI SD & Range \\
\hline Very underweight & 5 & 22.99 & 4.56 & 10.53 \\
\hline Slightly underweight & 68 & 21.06 & 2.05 & 7.87 \\
\hline About the right weight & 311 & 23.73 & 2.23 & 14.10 \\
\hline Slightly overweight & 103 & 28.09 & 3.82 & 21.09 \\
\hline Very overweight & 18 & 33.10 & 6.29 & 27 \\
\hline \multicolumn{5}{|l|}{ Females } \\
\hline Slightly underweight & 58 & 18.96 & 2.25 & 13.83 \\
\hline About the right weight & 790 & 21.74 & 1.97 & 13.91 \\
\hline Slightly overweight & 352 & 25.60 & 3.14 & 30.12 \\
\hline Very overweight & 40 & 33.25 & 7.03 & 30.27 \\
\hline
\end{tabular}


Table 9: Accurate and Inaccurate Perception of Weight Status by Normal Weight and Overweight $(n=1,736)$.

\begin{tabular}{|c|c|c|c|c|c|c|}
\hline \multirow[t]{2}{*}{ Males } & \multicolumn{2}{|c|}{$\begin{array}{l}\text { Accurate } \\
\text { Perception }\end{array}$} & \multicolumn{2}{|c|}{$\begin{array}{l}\text { Inaccurate } \\
\text { Perception }\end{array}$} & \multicolumn{2}{|c|}{ Total } \\
\hline & $\mathbf{n}$ & $\%$ & $\mathbf{n}$ & $\%$ & $\mathbf{n}$ & $\%$ \\
\hline Normal Weight & 222 & 70 & 97 & 30 & 319 & 69 \\
\hline Overweight/obese & 124 & 88 & 17 & 12 & 141 & 31 \\
\hline Total & 348 & 75 & 114 & 25 & 460 & 100 \\
\hline \multicolumn{5}{|l|}{ Females } & & \\
\hline Normal weight & 722 & 88 & 94 & 12 & 816 & 64 \\
\hline Overweight/obese & 313 & 68 & 147 & 32 & 460 & 36 \\
\hline Total & 1095 & 81 & 241 & 19 & 1276 & 100 \\
\hline
\end{tabular}


Table 10: Comparison of Weight Dissatisfaction by Operational and Affective Definitions

\begin{tabular}{|l|c|c|c|c|c|c|}
\hline \multirow{2}{*}{ Males } & \multicolumn{2}{|c|}{$\begin{array}{c}\text { Affective Weight } \\
\text { Dissatisfaction }\end{array}$} & $\begin{array}{c}\text { Affective Weight } \\
\text { Satisfaction }\end{array}$ & \multicolumn{2}{c|}{ Total } \\
\cline { 2 - 7 } & $\mathbf{n}$ & $\mathbf{\%}$ & $\mathbf{n}$ & \% & n & \% \\
\hline $\begin{array}{l}\text { Operational } \\
\begin{array}{l}\text { Weight } \\
\text { Dissatisfaction }\end{array}\end{array}$ & 34 & 33 & 70 & 67 & 104 & 61 \\
\hline $\begin{array}{l}\text { Operational } \\
\text { Weight Satisfaction }\end{array}$ & 3 & 5 & 63 & 95 & 66 & 39 \\
\hline Total & 37 & 22 & 133 & 78 & 170 & 100 \\
\hline $\begin{array}{l}\text { Females } \\
\text { 2 }\end{array}$ & 140 & 90 & 15 & 10 & 155 & 47 \\
\hline $\begin{array}{l}\text { Operational } \\
\begin{array}{l}\text { Weight } \\
\text { Dissatisfaction }\end{array}\end{array}$ & 80 & 47 & 92 & 53 & 172 & 53 \\
\hline $\begin{array}{l}\text { Operational } \\
\text { Weight Satisfaction }\end{array}$ & 220 & 67 & 107 & 33 & 327 & 100 \\
\hline Total & & & & & & \\
\hline
\end{tabular}

${ }^{1} 261$ (48\%) males were missing the affective item or were excluded from the operational definition and are missing from the analysis

$2871(62 \%)$ females were missing the affective item or were excluded from the | operational definition and are missing from the analysis 


\title{
APPENDIX A: College Environmental Behavioral Perception Survey, University of Rhode Island
}

\author{
CEPBS RI Spring 2015
}

Q174 University of Rhode Island College Environment Survey Department of Nutrition and Food Sciences Informed Consent You have been invited to take part in a research project described below. Students enrolled in selected URI classes will be given the opportunity to earn extra credit by completing the following survey. The purpose of the research is to see what students think about the college environment and to see how the environment affects their health-related behavior. This survey will be administered at 16 other colleges as part of a national research project by the Healthy Campus Research Consortium (HCRC). At URI, Tricia Uhoch, the Graduate Research Assistant conducting this study will be glad to answer any questions you may have. You can call her at 401-874-2674 or email the study email eatgreen.uri@gmail.com. You should feel free to ask questions. If you have more questions later, Professor Geoffrey Greene, the person mainly responsible for this study, 401-874-4028, will discuss them with you. You must be at least 18 years old to be in this research project. Description of the project: You have been asked to take part in the study that will ask you to complete a survey that will take about 25 minutes. What will be done: If you decide to take part in this study here is what will happen: you will complete an online survey. You will receive extra credit for completing the survey. You must indicate your agreement to participate and that you are at least 18 years of age to access the survey. Risks or discomfort: The survey should take about 25 minutes to complete and the questions being asked should not pose any discomfort. If any question poses discomfort the surveys, simply select the \&quot; Choose not to answer\&quot; response to that question. Your instructor will not have access to your responses. You will receive class credit for completing the surveys, regardless of whether you select \&quot;Choose not to answer\&quot; for any or all of the questions. Benefits of this study: You will receive class credit or extra credit added to your grade for this semester. Although you will not receive any benefits, the results of this study will help us assess how the college environment affects student health behavior which will help us work on improving the campus environment for future students. Confidentiality: Although you will provide your email and student ID as part of the survey, that information will be removed from your survey responses before data are analyzed. Your participation is recorded for purposes of obtaining class credit or extra credit. Your part in this study is confidential; however, you should understand that any form of communication over the Internet does carry a minimal loss of confidentiality. None of the information that will be analyzed will identify you by name. After class credit has been assigned, identifying information will be removed. The unidentifiable data will be stored in password-protected computer files by the HCRC which will be used by URI Department of Nutrition and Food Sciences researchers as well as other researchers in the HCRC for at least 3 years. Decision to quit at any time: The decision to take part in this study is up to you. You do not have to participate. If you decide to take part in the study, you may quit at any time. 
Whatever you decide will in no way adversely affect your grade in this or any other class, nor your status as a student at the University. You have the right to stop participating at any time, but once data have been entered and verified and the link between participant and code has been destroyed, we will not be able to remove your data. If you wish to quit, simply inform Tricia Uhoch at 401-874-2674 or Professor Geoffrey Greene at 401-874-4028 of your decision. Ongoing Research: This is part of ongoing research being conducted at the Department of Nutrition and Food Sciences. Rights and Complaints: If you are not satisfied with the way this study is performed, or have any questions about your rights as a research subject, you may discuss your complaints with Professor Geoffrey Greene or with the Office of Research Integrity at 401-874-4328, anonymously, if you choose. In addition, you may contact the office of the Vice President for Research and Economic Development, 70 Lower College Road, Suite 2, University of Rhode Island. You have read this Consent Form. Your questions have been answered. Checking "I agree to participate" on this form means that you understand the information in this explanation of the study and you agree to complete the survey and allow your data to be used for research. Please note that you must be at least 18 years of age in order to participate.

University of Rhode Island Institutional Review Board: \# HU1415-

066 Approval dates: 12/16/2014 to 12/15/2015

I I agree to participate and am at least 18 years of age (1)

I choose not to participate (2)

If I choose not to participate Is Selected, Then Skip To End of Survey

Q186 There are plenty of exercise classes offered at the rec center on campus.

O Strongly agree (1)

O Agree (2)

Neither Agree nor Disagree (3)

Disagree (4)

O Strongly disagree (5)

Choose not to answer (6)

Q188 There are policies (e.g. no cars on campus) on campus that promote physical activity.

Strongly agree (1)

Agree (2)

Neither Agree nor Disagree (3)

$\bigcirc$ Disagree (4)

S Strongly disagree (5)

Choose not to answer (6) 
Q190 There are policies (e.g. limits on sizes of sodas, minimum healthy items in vending machines) on campus that promote healthy eating.

O Strongly Agree (1)

Agree (2)

Neither Agree nor Disagree (3)

O Disagree (4)

Strongly disagree (5)

Choose not to answer (6)

Q192 Green eating is: Eating locally grown foods, limited amounts of processed/fast foods, eating meatless meals at least one day per week, choosing organic foods as much as possible, and only taking what you plan on eating. Based on the above definition for green eating, overall my campus promotes green eating.

Strongly Agree (1)

Agree (2)

Neither Agree nor Disagree (3)

$\bigcirc$ Disagree (4)

Strongly disagree (5)

Choose not to answer (6)

Q194 Healthy foods are available at grocery stores around campus.

O Strongly Agree (1)

Agree (2)

O Neither Agree nor Disagree (3)

O Disagree (4)

Strongly disagree (5)

I don't know because I don't shop at grocery stores around campus (6)

Choose not to answer (7)

Q196 The university's exercise facilities and equipment are in good condition.

O Strongly Agree (1)

Agree (2)

Neither Agree nor Disagree (3)

Disagree (4)

Strongly disagree (5)

Choose not to answer (6) 
Q198 The healthy foods on campus are more expensive than the unhealthy foods on campus.

Strongly Agree (1)

Agree (2)

Neither Agree nor Disagree (3)

Disagree (4)

Strongly disagree (5)

I don't know because I don't eat on campus. (6)

Choose not to answer (7)

Q200 The water in water fountains on campus tastes good.

Strongly Agree (1)

Agree (2)

Neither Agree nor Disagree (3)

$\bigcirc$ Disagree (4)

Strongly disagree (5)

I don't know because I don't use water fountains on campus. (6)

Choose not to answer (7)

Q202 There are safe places for me to walk on campus.

O Strongly Agree (1)

Agree (2)

Neither Agree nor Disagree (3)

O Disagree (4)

Strongly disagree (5)

Choose not to answer (6)

Q204 The stairs in most buildings on campus are clean and well lit.

O Strongly Agree (1)

Agree (2)

Neither Agree nor Disagree (3)

$\bigcirc$ Disagree (4)

Strongly disagree (5)

Choose not to answer (6) 
Q206 There are signs in buildings encouraging people to use the stairs.

O Strongly Agree (1)

Agree (2)

Neither Agree nor Disagree (3)

$\bigcirc$ Disagree (4)

Strongly disagree (5)

Choose not to answer (6)

Q208 The campus living environment allows for quiet and restful sleep.

Strongly Agree (1)

O Agree (2)

Neither Agree nor Disagree (3)

O Disagree (4)

Strongly disagree (5)

Choose not to answer (6)

Q210 There are programs on campus that promote stress management.

Strongly Agree (1)

O Agree (2)

Neither Agree nor Disagree (3)

O Disagree (4)

Strongly disagree (5)

Choose not to answer (6)

Q212 There are healthy foods available at restaurants on or around campus.

O Strongly Agree (1)

Agree (2)

Neither Agree nor Disagree (3)

$\bigcirc$ Disagree (4)

Strongly disagree (5)

I don't know because I don't eat at restaurants on or around campus. (6)

Choose not to answer (7)

Q214 There are lots of healthy choices in vending machines on campus.

O Strongly Agree (1)

Agree (2)

Neither Agree nor Disagree (3)

O Disagree (4)

Strongly disagree (5)

I don't know because I don't use vending machines on campus. (6)

Choose not to answer (7) 
Q216 There are enough exercise facilities and equipment on campus.

O Strongly Agree (1)

O Agree (2)

O Neither Agree nor Disagree (3)

O Disagree (4)

O Strongly disagree (5)

O Choose not to answer (6)

Q218 There are sports (intramural or club) available to play on campus.

O Strongly Agree (1)

O Agree (2)

O Neither Agree nor Disagree (3)

O Disagree (4)

Strongly disagree (5)

O Choose not to answer (6)

Q220 More bike racks are needed on campus.

O Strongly Agree (1)

O Agree (2)

O Neither Agree nor Disagree (3)

O Disagree (4)

O Strongly disagree (5)

Choose not to answer (6)

Q222 It is safe to walk around campus at night.

O Strongly Agree (1)

O Agree (2)

O Neither Agree nor Disagree (3)

O Disagree (4)

Strongly disagree (5)

O Choose not to answer (6)

Q224 There are healthy foods available where I usually eat in dining halls on campus.

O Strongly Agree (1)

O Agree (2)

Neither Agree nor Disagree (3)

O Disagree (4)

O Strongly disagree (5)

I don't know because I don't eat in dining halls on campus. (6)

C Choose not to answer (7) 
Q226 There are healthy foods available at convenience stores on campus.

O Strongly Agree (1)

Agree (2)

Neither Agree nor Disagree (3)

$\bigcirc$ Disagree (4)

Strongly disagree (5)

I don't know because I don't shop at convenience stores on campus. (6)

Choose not to answer (7)

Q228 There are signs telling me which foods are healthy in vending machines on campus.

Strongly Agree (1)

O Agree (2)

Neither Agree nor Disagree (3)

O Disagree (4)

Strongly disagree (5)

I don't know because I don't use the vending machines on campus. (6)

Choose not to answer (7)

Q230 The water/drinking fountains on campus look clean.

O Strongly Agree (1)

Agree (2)

Neither Agree nor Disagree (3)

O Disagree (4)

Strongly disagree (5)

I don't know because I don't use water fountains on campus (6)

Choose not to answer (7)

Q232 Most buildings on campus have water/drinking fountains.

O Strongly Agree (1)

Agree (2)

Neither Agree nor Disagree (3)

Disagree (4)

O Strongly disagree (5)

I don't know because I don't use water fountains on campus (6)

Choose not to answer (7)

Q234 There are plenty of opportunities on campus to be moderately or vigorously active on campus. (Vigorous physical activities refer to activities that take hard physical effort and make you breathe much harder than normal or make your heart beat much harder than normal. Moderate activities refer to activities that take 
moderate physical effort and make you breathe somewhat harder than normal or make your heart beat somewhat harder than normal.)

Strongly Agree (1)

Agree (2)

Neither Agree nor Disagree (3)

Disagree (4)

Strongly disagree (5)

Choose not to answer (6)

Q236 It is safe to bike around campus.

O Strongly Agree (1)

Agree (2)

Neither Agree nor Disagree (3)

O Disagree (4)

Strongly disagree (5)

Choose not to answer (6)

Q238 The university encourages students to eat healthy.

O Strongly Agree (1)

Agree (2)

Neither Agree nor Disagree (3)

O Disagree (4)

Strongly disagree (5)

Choose not to answer (6)

Q240 There are healthy foods available on campus.

Strongly Agree (1)

Agree (2)

O Neither Agree nor Disagree (3)

$\bigcirc$ Disagree (4)

Strongly disagree (5)

I don't know. (6)

Choose not to answer (7) 
Q230 I look for healthy food options when I shop and eat (including in grocery stores, vending machines, dining halls, restaurants, convenience stores and food courts/snack bars).

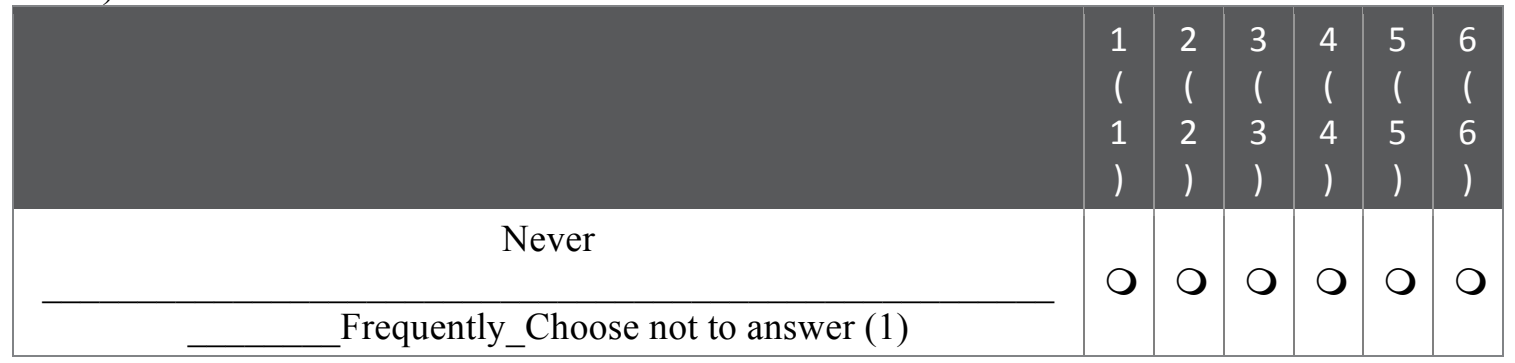

Q232 I use the university's exercise facilities and equipment.

\begin{tabular}{c|c|c|c|c|c|c|c|} 
& 1 & 2 & 3 & 4 & 5 & 6 \\
& $(1$ & ( & ( & 1 & ( & ( \\
& 1 & 2 & 3 & 4 & 5 & 6 \\
\hline Never & 1 & 1 & 1 & 1 & 1 & 1 \\
\hline Frequently_Choose not to answer (1) & 0 & 0 & 0 & 0 & 0 & 0 \\
\hline
\end{tabular}

Q234 I use the stairs in most buildings on campus.

\begin{tabular}{|c|l|l|l|l|l|l|} 
& 1 & 2 & 3 & 4 & 5 & 6 \\
& $(1$ & 1 & ( & 1 & ( & 1 \\
& 1 & 2 & 3 & 4 & 5 & 6 \\
\hline Never & 1 & 1 & 1 & 1 & 1 & 1 \\
\hline Frequently_Choose not to answer (1) & 0 & 0 & 0 & 0 & 0 & 0 \\
\hline
\end{tabular}

Q236 I walk on campus during the day.

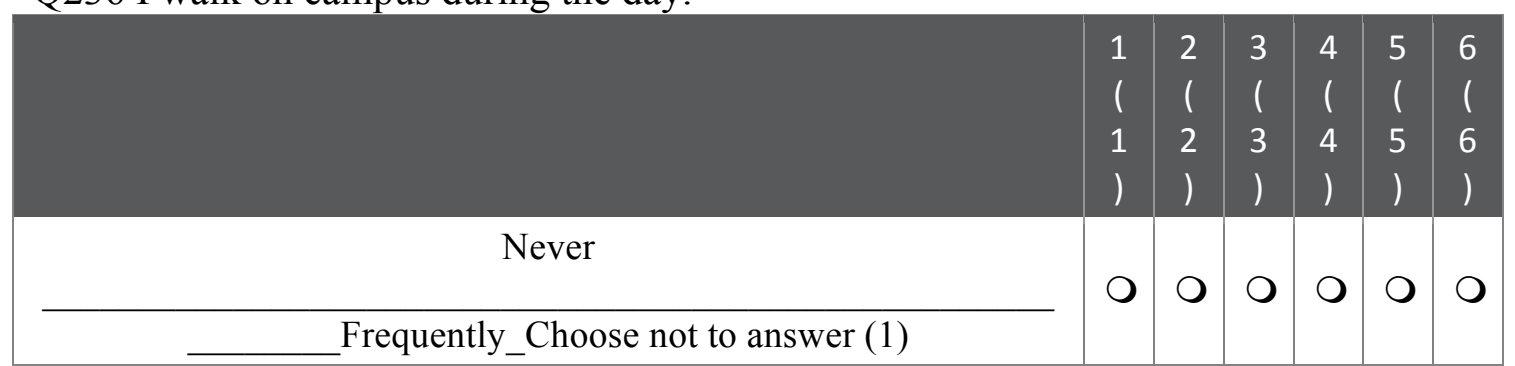


Q238 I walk around on campus at night.

\begin{tabular}{c|c|c|c|c|c|c|c|} 
& 1 & 2 & 3 & 4 & 5 & 6 \\
& 1 & ( & ( & ( & ( & ( \\
Never & 1 & 2 & 3 & 4 & 5 & 6 \\
\hline Frequently_Choose not to answer (1) & 0 & 0 & 0 & 0 & 0 & 0 \\
\hline
\end{tabular}

Q240 I participate in exercise classes offered at the rec center on campus.

\begin{tabular}{c|c|c|c|c|c|c|c|} 
& 1 & 2 & 3 & 4 & 5 & 6 \\
& ( & 1 & 1 & 1 & ( & 1 \\
Never & 1 & 2 & 3 & 4 & 5 & 6 \\
\hline Frequently_Choose not to answer (1) & 0 & 0 & 0 & 0 & 0 & 0 \\
\hline
\end{tabular}

Q242 I play sports (intramural or club) on campus.

\begin{tabular}{|c|c|c|c|c|c|c|} 
& 1 & 2 & 3 & 4 & 5 & 6 \\
& $(1$ & ( & ( & 1 & ( & ( \\
& 1 & 2 & 3 & 4 & 5 & 6 \\
\hline Never & 1 & 1 & 1 & 1 & 1 & 1 \\
\hline Frequently_Choose not to answer (1) & 0 & 0 & 0 & 0 & 0 & 0 \\
\hline
\end{tabular}

Q244 I bike on campus.

\begin{tabular}{|c|c|c|c|c|c|c|}
\hline (2. & $\begin{array}{l}1 \\
( \\
1 \\
)\end{array}$ & $\begin{array}{l}2 \\
1 \\
2 \\
1\end{array}$ & $\begin{array}{l}3 \\
1 \\
3 \\
1\end{array}$ & $\begin{array}{l}4 \\
1 \\
4 \\
1\end{array}$ & $\begin{array}{l}5 \\
1 \\
5 \\
1\end{array}$ & $\begin{array}{l}6 \\
1 \\
6 \\
1\end{array}$ \\
\hline Never & \multirow[t]{2}{*}{0} & \multirow[t]{2}{*}{0} & \multirow[t]{2}{*}{0} & \multirow{2}{*}{0} & \multirow[t]{2}{*}{0} & \multirow[t]{2}{*}{0} \\
\hline Frequently Choose not to answer (1) & & & & & & \\
\hline
\end{tabular}


Q246 I use water fountains on campus.

\begin{tabular}{c|c|c|c|c|c|c|c|} 
& 1 & 2 & 3 & 4 & 5 & 6 \\
& 1 & 1 & 1 & 1 & 1 & 1 \\
& 1 & 2 & 3 & 4 & 5 & 6 \\
\hline Never & 1 & 1 & 1 & 1 & 1 & 1 \\
\hline Frequently_Choose not to answer (1) & & 0 & 0 & 0 & 0 & 0 & 0 \\
\hline
\end{tabular}

Q248 I participate in programs on campus that promote health (healthy eating, physical activity, stress management).

\begin{tabular}{c|c|c|c|c|c|c|c|} 
& 1 & 2 & 3 & 4 & 5 & 6 \\
& 1 & ( & ( & ( & ( & ( \\
Never & 1 & 2 & 3 & 4 & 5 & 6 \\
\hline Frequently_Choose not to answer (1) & 0 & 0 & 0 & 0 & 0 & 0 \\
\hline
\end{tabular}

Q250 What is your height?

$\square$ If you choose not to answer, please type CNA in the box. (1)

$\square$ Feet (2)

$\square$ Inches (3)

Q252 The next four questions ask about body weight.

Q254 What is your weight (in pounds)?

O If you choose not to answer, please type CNA in the box (1)

Pounds (2)

Q256 How do you describe your weight?

$\mathrm{O}$ Very underweight (1)

Slightly underweight (2)

O About the right weight (3)

Slightly overweight (4)

V Very overweight (5)

Choose not to answer (6) 
Q258 Which of the following are you trying to do about your weight?

O Lose weight (1)

Gain weight (2)

O Stay the same weight (3)

I am not trying to do anything about my weight (4)

Choose not to answer (5)

Q260 During the past 12 months, have you tried to lose weight?

$\bigcirc$ Yes (1)

No (2)

Choose not to answer (3)

Don't Know (4)

Q176 How do you feel about your current weight?

O I am happy with my current weight. (1)

I don't care about my current weight. (2)

I am upset about my current weight. (3)

Choose not to answer. (4)

Q262 How old are you?

O 18 (2)

O 19 (3)

○ 20 (4)

○ $21(5)$

○ $22(6)$

○ $23(7)$

○ 24 (8)

More than 24 years old (9)

Q264 What is your current gender identity?

O Male (1)

Female (2)

Trans male/Trans man (3)

Trans female/Trans woman (4)

Genderqueer/Gender non-conforming (5)

Different identity (please state): (6)

Choose not to answer (7) 
Q266 Are you Hispanic or Latino?

O Yes (1)

O No (2)

I I don't know/Not sure (3)

O Choose not to answer (4)

Q268 Which one or more of the following would you say is your race?

O White (1)

O Black or African American (2)

O Asian (3)

O Native Hawaiian or Other Pacific Islander (4)

O American Indian or Alaska Native (5)

Other (please specify) (6)

Choose not to answer (7)

Q270 What is your year in school?

O Freshman (1)

O Sophomore (2)

O Junior (3)

O Senior (4)

O Graduate (5)

O Choose not to answer (6)

Q272 Where do you live?

O Campus residence hall (1)

O Sorority or fraternity (2)

Other university/college housing (3)

Off campus housing (4)

O Parent or guardian's home (5)

Other, please specify (6)

O Choose not to answer (7) 
Q274 Where is the university you attend?

O Alabama (1)

O Florida (2)

O Maine (3)

O Kansas (4)

O New York (5)

O Tennessee (6)

O South Dakota (7)

O West Virginia (8)

O Rhode Island (9)

Q276 How would you define your current relationship status?

O Single (1)

O In a committed relationship (2)

O Choose not to answer (3)

Q278 How many hours a week do you work for pay during the school year?

O I do not work (1)

O 1 to 9 hours (2)

O 10 to 19 hours (3)

O 20 to 29 hours (4)

O 30 to 39 hours (5)

O 40 hours (6)

O More than 40 hours (7)

O Choose not to answer (8)

Q280 My overall GPA is

O $3.5-4.0$ (1)

O $3.0-3.49(2)$

O $2.50-2.9(3)$

O $2.0-2.49(4)$

O Under 2.0 (5)

Choose not to answer (6)

Q178 Are you a vegetarian (Do not eat meat, chicken, or fish)?

O Yes (1)

No (2)

Choose not to answer (3) 
Q179 On average, how many days a week do you consume red meat?

O Never (1)

O 1 time per week (2)

O 2 times per week (3)

O 3 times per week (4)

O 4 times per week (5)

O 5 times per week (6)

O 6 times per week (7)

O 7 or more times per week (8)

Choose not to answer (9)

Q282 Think about what you usually ate last month. Please think about all the fruits and vegetables that you ate last month. Include those that were: Raw and cooked, Eaten as snacks and at meals Eaten at home and away from home (restaurants, friends, take-out), and Eaten alone and mixed with other foods. Report how many times per month, week, or day you ate each food, and if you ate it, how much you usually had.Choose the best answer for each question. Mark only one response for each question.

Q284 Over the last month, how many times per month, week, or day did you drink $100 \%$ juice such as orange, apple, grape, or grapefruit juice? Do not count fruit drinks like Kool-Aid, lemonade, Hi-C, cranberry juice drink, Tang, and Twister. Include juice you drank at all mealtimes and between meals.

O never (1)

O 1-3 times last month (2)

O 1-2 times per week (3)

O 3-4 times per week (4)

O 5-6 times per week (5)

O 1 time per day (6)

O 2 times per day (7)

O 3 times per day (8)

O 4 times per day (9)

O 5 or more times per day (10)

O Choose not to answer (11)

Q286 Each time you drank 100\% juice, how much did you usually drink?

O Did not drink $100 \%$ juice (1)

O Less than $3 / 4$ cup (less than 6 ounces) (2)

O $3 / 4$ to $1 \frac{1 / 4}{4}$ cup (6 to 10 ounces) (3)

O $1 \frac{1 / 4}{4}$ to 2 cups (10 to 16 ounces) (4)

O More than 2 cups (more than 16 ounces) (5)

Choose not to answer (6) 
Q288 Over the last month, how many times per month, week, or day did you eat fruit? Count any kind of fruit-fresh, canned, and frozen. Do not count juices. Include fruit you ate at all mealtimes and for snacks.

O never (1)

O 1-3 times last month (2)

O 1-2 times per week (3)

O 3-4 times per week (4)

O 5-6 times per week (5)

O 1 time per day (6)

O 2 times per day (7)

O 3 times per day (8)

O 4 times per day (9)

O 5 or more times per day (10)

O Choose not to answer (11)

Q290 Each time you ate fruit, how much did you usually eat?

O Did not eat fruit (1)

L Less than 1 medium fruit (less than $1 / 2$ cup) (2)

O 1 medium fruit (about $1 / 2$ cup) (3)

O 2 medium fruits (about 1 cup) (4)

O More than 2 medium fruits (more than 1 cup) (5)

Choose not to answer (6)

Q292 Over the last month, how often did you eat lettuce salad (with or without other vegetables)?

O never (1)

O 1-3 times last month (2)

O 1-2 times per week (3)

O 3-4 times per week (4)

O 5-6 times per week (5)

O 1 time per day (6)

O 2 times per day (7)

O 3 times per day (8)

O 4 times per day (9)

O 5 or more times per day (10)

O Choose not to answer (11) 
Q294 Each time you ate lettuce salad, how much did you usually eat?

O Did not eat lettuce salad (1)

O About $1 / 2$ cup (2)

O About 1 cup (3)

O About 2 cups (4)

O More than 2 cups (5)

Choose not to answer (6)

Q296 Over the last month, how often did you eat French fries or fried potatoes?

O never (1)

O 1-3 times last month (2)

O 1-2 times per week (3)

O 3-4 times per week (4)

O 5-6 times per week (5)

O 1 time per day (6)

O 2 times per day (7)

O 3 times per day (8)

O 4 times per day (9)

O 5 or more times per day (10)

Choose not to answer (11)

Q298 Each time you ate French fries or fried potatoes, how much did you usually eat?

O Did not eat French fries or fried potatoes (1)

O Small order or less (About 1 cup or less) (2)

O Medium order (About $1 \frac{1 / 2}{2}$ cups) (3)

O Large order (About 2 cups) (4)

O Super-Size order or more (About 3 cups or more) (5)

O Choose not to answer (6) 
Q300 Over the last month, how often did you eat other white potatoes? Count baked, boiled, and mashed potatoes, potato salad, and white potatoes that were not fried.

O never (1)

O 1-3 times last month (2)

O 1-2 times per week (3)

O 3-4 times per week (4)

O 5-6 times per week (5)

O 1 time per day (6)

O 2 times per day (7)

O 3 times per day $(8)$

O 4 times per day (9)

O 5 or more times per day (10)

O Choose not to answer (11)

Q302 Each time you ate these potatoes, how much did you usually eat?

O Did not eat these types of potatoes (1)

O 1 small potato or less ( $1 / 2$ cup or less) (2)

O 1 medium potato ( $1 / 2$ to 1 cup) (3)

O 1 large potato (1 to $1 \frac{1 / 2}{2}$ cups) (4)

O 2 medium potatoes or more ( $1 \frac{1}{2}$ cups or more) (5)

O Choose not to answer (6)

Q304 Over thelast month, how often did you eat cooked dried beans? Count bakedbeans, bean soup, refried beans, pork and beans and other bean dishes.

O never (1)

O 1-3 times last month (2)

O 1-2 times per week (3)

O 3-4 times per week (4)

O 5-6 times per week (5)

O 1 time per day (6)

O 2 times per day (7)

O 3 times per day (8)

O 4 times per day (9)

O 5 or more times per day (10)

O Choose not to answer (11) 
Q306 Each time you ate these beans, how much did you usually eat?

$\mathrm{O}$ Did not eat cooked dried beans (1)

Less than $1 / 2$ cup (2)

O $1 / 2$ to 1 cup (3)

O 1 to $1 \frac{1 / 2}{2}$ cups (4)

More than $1 \frac{1}{2}$ cups (5)

Choose not to answer (6)

Q308 Over the last month, how often did you eat other vegetables? DO NOT COUNT: Lettuce salads White potatoes Cooked dried beans Vegetables in mixtures, such as in sandwiches, omelets, casseroles, Mexican dishes, stews, stirfry, soups, etc. Rice COUNT: All other vegetables-raw, cooked, canned, and frozen

never (1)

O 1-3 times last month (2)

O 1-2 times per week (3)

3-4 times per week (4)

5-6 times per week (5)

O 1 time per day (6)

O 2 times per day (7)

O 3 times per day (8)

O 4 times per day (9)

5 or more times per day (10)

Choose not to answer (11)

Q310 Each of these times that you ate other vegetables, how much did you usually eat?

O Did not eat these vegetables (1)

Less than $1 / 2$ cup (2)

O $1 / 2$ to 1 cup (3)

O 1 to 2 cups (4)

More than 2 cups (5)

Choose not to answer (6) 
Q312 Over the last month, how often did you eat tomato sauce? Include tomato sauce on pasta or macaroni, rice, pizza and other dishes.

O never (1)

1-3 times last month (2)

O 1-2 times per week (3)

3-4 times per week (4)

5-6 times per week (5)

O 1 time per day (6)

2 times per day (7)

O 3 times per day (8)

O times per day (9)

5 or more times per day (10)

Choose not to answer (11)

Q314 Each time you ate tomato sauce, how much did you usually eat?

Did not eat tomato sauce (1)

About $1 / 4 \operatorname{cup}(2)$

About $1 / 2 \operatorname{cup}(3)$

About 1 cup (4)

More than 1 cup (5)

Choose not to answer (6)

Q316 Over the last month, how often did you eat vegetable soups? Include tomato soup, gazpacho, beef with vegetable soup, minestrone soup, and other soups made with vegetables.

O never (1)

1-3 times last month (2)

O 1-2 times per week (3)

O 3-4 times per week (4)

O 5-6 times per week (5)

O 1 time per day (6)

O 2 times per day (7)

O 3 times per day (8)

O 4 times per day (9)

O 5 or more times per day (10)

O Choose not to answer (11) 
Q318 Each time you ate vegetable soup, how much did you usually eat?

O Did not eat vegetable soup (1)

O Less than 1 cup (2)

O 1 to 2 cups (3)

O 2 to 3 cups (4)

O More than 3 cups (5)

C Choose not to answer (6)

Q320 Over the last month, how often did you eat mixtures that included vegetables?

Count such foods as sandwiches, casseroles, stews, stir-fry, omelets, and tacos.

O never (1)

O 1-3 times last month (2)

O 1-2 times per week (3)

O 3-4 times per week (4)

O 5-6 times per week (5)

O 1 time per day (6)

O 2 times per day (7)

O 3 times per day (8)

O 4 times per day (9)

O 5 or more times per day (10)

O Choose not to answer (11)

Q322 1. Green Eating is: Eating locally grown foods, limited amounts of processed/fast foods, eating meatless meals at least one day per week, choosing organic foods as much as possible, and only taking what you plan on eating.Are you a green eater?

O No, and I do not intend to start within the next 6 months (1)

O No, but I am thinking about becoming a green eater within the next 6 months (2)

O No, but I am planning on becoming a green eater within the next 30 days (3)

O Yes, I am a green eater and have been for less than 6 months (4)

O Yes, I am a green eater and have been doing so for 6 months or more (5)

O I choose not to answer (6) 
Q324 2. Please select the answer that BEST describes your usual behavior

\begin{tabular}{|c|c|c|c|c|c|c|}
\hline & $1(1)$ & $2(2)$ & $3(3)$ & $4(4)$ & $5(5)$ & $6(6)$ \\
\hline $\begin{array}{l}\text { Locally } \\
\text { grown foods } \\
\text { are grown } \\
\text { within } 100 \\
\text { miles of } \\
\text { your } \\
\text { location. } \\
\text { Based on } \\
\text { this, how } \\
\text { often do } \\
\text { you eat } \\
\text { locally } \\
\text { grown } \\
\text { foods? (1) }\end{array}$ & 0 & 0 & 0 & 0 & 0 & 0 \\
\hline $\begin{array}{l}\text { When in } \\
\text { season, how } \\
\text { often do } \\
\text { you shop at } \\
\text { farmer's } \\
\text { markets? (2) }\end{array}$ & 0 & 0 & 0 & 0 & 0 & 0 \\
\hline $\begin{array}{l}\text { How often } \\
\text { do you } \\
\text { choose } \\
\text { foods that } \\
\text { are labeled } \\
\text { certified } \\
\text { organic? (3) }\end{array}$ & 0 & 0 & 0 & 0 & 0 & 0 \\
\hline $\begin{array}{l}\text { How often } \\
\text { do you buy } \\
\text { meat or } \\
\text { poultry } \\
\text { products } \\
\text { labeled } \\
\text { "free range" } \\
\text { or "cage } \\
\text { free"? (4) }\end{array}$ & 0 & 0 & 0 & 0 & 0 & 0 \\
\hline $\begin{array}{c}\text { How often } \\
\text { do you } \\
\text { select } \\
\text { meats, } \\
\text { poultry, and } \\
\text { dairy } \\
\text { products } \\
\text { that are } \\
\text { raised } \\
\text { without }\end{array}$ & 0 & 0 & 0 & 0 & 0 & 0 \\
\hline
\end{tabular}




\begin{tabular}{|c|c|c|c|c|c|c|}
\hline $\begin{array}{c}\text { antibiotics } \\
\text { or } \\
\text { hormones? } \\
\quad(5) \\
\text { How often } \\
\text { do you } \\
\text { select food } \\
\text { or } \\
\text { beverages } \\
\text { that are } \\
\text { labeled fair } \\
\text { trade } \\
\text { certified? } \\
\text { (6) }\end{array}$ & 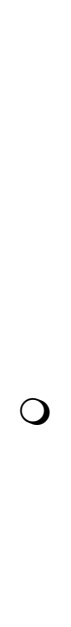 & $\bigcirc$ & $\mathrm{O}$ & 0 & 0 & 0 \\
\hline
\end{tabular}


Q326 3. Here are some advantages and disadvantages of green eating. Please indicate HOW IMPORTANT each one is in your deciding to eat green.

\begin{tabular}{|c|c|c|c|c|c|c|}
\hline & 1 (1) & 2 (2) & $3(3)$ & $4(4)$ & $5(5)$ & $6(6)$ \\
\hline $\begin{array}{l}\text { Eating green } \\
\text { is not } \\
\text { practical in } \\
\text { my life right } \\
\text { now (1) }\end{array}$ & 0 & 0 & 0 & 0 & 0 & 0 \\
\hline $\begin{array}{l}\text { Eating green } \\
\text { can be too } \\
\text { expensive } \\
\text { (2) }\end{array}$ & 0 & 0 & 0 & 0 & 0 & 0 \\
\hline $\begin{array}{l}\text { By eating } \\
\text { green, I can } \\
\text { help protect } \\
\text { the planet } \\
\text { (3) }\end{array}$ & 0 & 0 & 0 & 0 & 0 & 0 \\
\hline $\begin{array}{l}\text { Eating green } \\
\text { would be } \\
\text { too difficult } \\
\text { (4) }\end{array}$ & $\mathrm{O}$ & 0 & 0 & 0 & 0 & 0 \\
\hline $\begin{array}{c}\text { Eating } \\
\text { minimally } \\
\text { processed } \\
\text { foods is } \\
\text { better for } \\
\text { my health } \\
\text { (5) }\end{array}$ & 0 & 0 & 0 & 0 & 0 & $\mathrm{O}$ \\
\hline $\begin{array}{l}\text { By eating } \\
\text { green I can } \\
\text { improve the } \\
\text { quality of } \\
\text { my diet (6) }\end{array}$ & 0 & 0 & 0 & 0 & 0 & 0 \\
\hline $\begin{array}{l}\text { By eating } \\
\text { green I can } \\
\text { support the } \\
\text { local } \\
\text { economy (7) }\end{array}$ & 0 & 0 & 0 & 0 & 0 & 0 \\
\hline $\begin{array}{l}\text { Sustainably } \\
\text { produced } \\
\text { foods aren't } \\
\text { available to } \\
\text { me (8) }\end{array}$ & 0 & 0 & 0 & 0 & 0 & $\mathrm{O}$ \\
\hline $\begin{array}{l}\text { I am proud } \\
\text { that I can } \\
\text { help the } \\
\text { environment }\end{array}$ & O & 0 & 0 & O & $\mathrm{O}$ & 0 \\
\hline
\end{tabular}




\begin{tabular}{|c|c|c|c|c|c|c|}
\hline $\begin{array}{l}\text { by eating } \\
\text { green }(9)\end{array}$ & & & & & & \\
\hline $\begin{array}{l}\text { I can't find } \\
\text { green foods } \\
\text { where I } \\
\text { shop (10) }\end{array}$ & 0 & 0 & 0 & 0 & 0 & 0 \\
\hline
\end{tabular}

Q328 REMINDER: Green Eating is: Eating locally grown foods, limited amounts of processed/fast foods, eating meatless meals at least one day per week, choosing organic foods as much as possible, and only taking what you plan on eating. Please rate HOW CONFIDENT you feel that you could eat green under each of the following circumstances?

\begin{tabular}{|c|c|c|c|c|c|c|}
\hline & $1(1)$ & $2(2)$ & $3(3)$ & $4(4)$ & $5(5)$ & $6(6)$ \\
\hline $\begin{array}{l}\text { When I am } \\
\text { busy (1) }\end{array}$ & 0 & 0 & 0 & 0 & 0 & 0 \\
\hline $\begin{array}{l}\text { When I am } \\
\text { at school } \\
\text { during the } \\
\text { semester (2) }\end{array}$ & 0 & 0 & 0 & 0 & 0 & 0 \\
\hline $\begin{array}{l}\text { When I am } \\
\text { at home (3) }\end{array}$ & 0 & 0 & 0 & 0 & 0 & 0 \\
\hline $\begin{array}{l}\text { When it is } \\
\text { inconvenient } \\
\text { (4) }\end{array}$ & 0 & 0 & 0 & 0 & 0 & 0 \\
\hline $\begin{array}{c}\text { When I am } \\
\text { with my } \\
\text { family (5) }\end{array}$ & 0 & 0 & 0 & 0 & 0 & 0 \\
\hline $\begin{array}{l}\text { When I go } \\
\text { out to eat (6) }\end{array}$ & 0 & 0 & 0 & 0 & 0 & 0 \\
\hline $\begin{array}{l}\text { When I eat } \\
\text { in the dining } \\
\text { halls or } \\
\text { cafeterias } \\
\text { (7) }\end{array}$ & 0 & 0 & 0 & 0 & 0 & 0 \\
\hline $\begin{array}{c}\text { Over the } \\
\text { summer }(8)\end{array}$ & 0 & 0 & 0 & 0 & 0 & 0 \\
\hline
\end{tabular}


Q330 Ten-Item Personality Inventory-(TIPI) Here are a number of personality traits that may or may not apply to you. Please indicate the extent to which you agree or disagree with each statement. You should rate the extent to which the pair of traits applies to you, even if one characteristic applies more strongly than the other. I see myself as:

\begin{tabular}{|c|c|c|c|c|c|c|c|c|}
\hline & $\begin{array}{l}\text { Disagre } \\
\mathrm{e} \\
\text { strongl } \\
\text { y (1) }\end{array}$ & $\begin{array}{c}\text { Disagree } \\
\text { moderate } \\
\text { ly (2) }\end{array}$ & $\begin{array}{c}\text { Disagre } \\
\text { e a } \\
\text { little } \\
\text { (3) }\end{array}$ & $\begin{array}{c}\text { Neithe } \\
r \text { agree } \\
\text { nor } \\
\text { disagre } \\
\text { e (4) }\end{array}$ & $\begin{array}{c}\text { Agre } \\
\text { e a } \\
\text { little } \\
(5)\end{array}$ & $\begin{array}{c}\text { Agree } \\
\text { moderate } \\
\text { ly (6) }\end{array}$ & $\begin{array}{c}\text { Agree } \\
\text { strongl } \\
\text { y (7) }\end{array}$ & $\begin{array}{l}\text { Choos } \\
\text { e not } \\
\text { to } \\
\text { answ } \\
\text { er (8) }\end{array}$ \\
\hline Extroverted & & & & & & & & \\
\hline $\begin{array}{c}\text { enthusiastic } \\
. \text { (1) }\end{array}$ & 0 & 0 & 0 & 0 & $\mathrm{O}$ & 0 & 0 & 0 \\
\hline $\begin{array}{l}\text { Critical, } \\
\text { quarrelsom } \\
\text { e. (2) }\end{array}$ & 0 & 0 & O & O & $\mathrm{O}$ & 0 & $\mathrm{O}$ & O \\
\hline $\begin{array}{l}\text { Dependable } \\
\text {, self- } \\
\text { disciplined. } \\
\text { (3) }\end{array}$ & 0 & 0 & 0 & 0 & 0 & 0 & 0 & 0 \\
\hline $\begin{array}{l}\text { Anxious, } \\
\text { easily } \\
\text { upset. (4) }\end{array}$ & 0 & 0 & 0 & 0 & O & 0 & $\mathrm{O}$ & 0 \\
\hline $\begin{array}{c}\text { Open to } \\
\text { new } \\
\text { experiences } \\
\text {, complex. } \\
\quad \text { (5) }\end{array}$ & 0 & 0 & 0 & O & O & 0 & $\mathrm{O}$ & 0 \\
\hline $\begin{array}{l}\text { Reserved, } \\
\text { quiet. (6) }\end{array}$ & 0 & 0 & 0 & O & $\mathrm{O}$ & 0 & 0 & 0 \\
\hline $\begin{array}{l}\text { Sympatheti } \\
\text { c, warm. } \\
\text { (7) }\end{array}$ & 0 & $\mathrm{O}$ & 0 & $\mathrm{O}$ & $\mathrm{O}$ & 0 & 0 & 0 \\
\hline $\begin{array}{c}\text { Disorganize } \\
\text { d, careless. } \\
\text { (8) }\end{array}$ & 0 & O & 0 & 0 & $\mathrm{O}$ & 0 & 0 & 0 \\
\hline $\begin{array}{c}\text { Calm, } \\
\text { emotionally } \\
\text { stable. (9) }\end{array}$ & 0 & O & 0 & 0 & 0 & 0 & 0 & 0 \\
\hline $\begin{array}{c}\text { Convention } \\
\text { al, } \\
\text { uncreative. } \\
\text { (10) }\end{array}$ & 0 & 0 & 0 & 0 & 0 & 0 & 0 & 0 \\
\hline
\end{tabular}


Q332 How Active Are You? We are interested in finding out about the kinds of physical activities that people do as part of their everyday lives. The questions will ask you about the time you spent being physically active in the last 7 days. Please answer each question even if you do not consider yourself to be an active person. Please think about the activities you do at work, as part of your house and yard work, to get from place to place, and in your spare time for recreation, exercise or sport. Think about all the vigorous activities that you did in the last 7 days. Vigorous physical activities refer to activities that take hard physical effort and make you breathe much harder than normal or make your heart beat much harder than normal. Think only about those vigorous physical activities that you did for at least 10 minutes at a time, such as running, aerobics, heavy yard work, or anything else that causes large increases in breathing or heart rate.

Q334 During the last 7 days, on how many days did you do vigorous physical activities like heavy lifting, digging, aerobics, or fast bicycling?
O 0 days (1)
O 1 day (2)
O 2 days (3)
O 3 days (4)
O 4 days (5)
O 5 days (6)
O 6 days (7)
O 7 days (8)
Choose not to answer (9) 
Q336 How much time did you usually spend doing vigorous physical activities on one of those days?

Did not do vigorous physical activities (1)

O 10 minutes (2)

O 20 minutes (3)

O 30 minutes (4)

O 40 minutes (5)

O 50 minutes (6)

O 60 minutes (7)

O 70 minutes ( $1 \mathrm{hr} 10 \mathrm{~min})(8)$

O 80 minutes ( $1 \mathrm{hr} 20 \mathrm{~min})(9)$

O 90 minutes (1 hr $30 \mathrm{~min})(10)$

O 100 minutes (1 hr $40 \mathrm{~min})(11)$

O 110 minutes ( $1 \mathrm{hr} 50 \mathrm{~min})(12)$

O 120 minutes (2 hrs) (13)

O 130 minutes (2 hrs $10 \mathrm{~min})(14)$

O 140 minutes ( $2 \mathrm{hrs} 20 \mathrm{~min})(15)$

O 150 minutes (2 hrs $30 \mathrm{~min})(16)$

O 160 minutes ( $2 \mathrm{hrs} 40 \mathrm{~min})(17)$

O 170 minutes (2 hrs $50 \mathrm{~min})(18)$

O $180+$ minutes ( 3 hrs or more) (19)

O Don't know/not sure (20)

Choose not to answer (21)

Q338 Think about all the moderate activities that you did in the last 7 days. Moderate activities refer to activities that take moderate physical effort and make you breathe somewhat harder than normal or make your heart beat somewhat harder than normal. Think only about those physical activities that you did for at least 10 minutes at a time, such as brisk walking, bicycling, vacuuming, gardening, or anything else that causes some increase in breathing or heart rate. 
Q340 During the last 7 days, on how many days did you do moderate physical activities like carrying light loads, bicycling at a regular pace, or doubles tennis? Do not include walking.

O 0 days (1)

O 1 day (2)

2 days (3)

O 3 days (4)

4 days (5)

5 days (6)

6 days (7)

O 7 days (8)

Choose not to answer (9)

Q342 How much time did you usually spend doing moderate physical activities on one of those days?

Did not do moderate physical activities (1)

O 10 minutes (2)

O 20 minutes (3)

O 30 minutes (4)

O 40 minutes (5)

50 minutes (6)

O 60 minutes (7)

O 70 minutes (1 hr $10 \mathrm{~min}$ ) (8)

O 80 minutes ( $1 \mathrm{hr} 20 \mathrm{~min}$ ) (9)

O 90 minutes (1 hr $30 \mathrm{~min}$ ) (10)

O 100 minutes (1 hr $40 \mathrm{~min})(11)$

O 110 minutes ( $1 \mathrm{hr} 50 \mathrm{~min}$ ) (12)

O 120 minutes (2 hrs) (13)

O 130 minutes (2 hrs $10 \mathrm{~min})(14)$

O 140 minutes (2 hrs $20 \mathrm{~min}$ ) (15)

O 150 minutes (2 hrs $30 \mathrm{~min})(16)$

O 160 minutes (2 hrs $40 \mathrm{~min}$ ) (17)

O 170 minutes ( $2 \mathrm{hrs} 50 \mathrm{~min})(18)$

O $180+$ minutes (3 hrs or more) (19)

Don't know/not sure (20)

O Choose not to answer (21)

Q344 Think about the time you spent walking in the last 7 days. This includes at work and at home, walking to travel from place to place, and any other walking that you might do solely for recreation, sport, exercise or leisure. 
Q346 During the last 7 days, on how many days did you walk for at least 10 minutes at a time?

O days (1)

1 day (2)

2 days (3)

O 3 days (4)

4 days (5)

O 5 days (6)

6 days (7)

7 days (8)

Choose not to answer (9)

Q348 How much time did you usually spend walking on one of those days?

D Did not walk (1)

O 10 minutes (2)

O 20 minutes (3)

O 30 minutes (4)

O 40 minutes (5)

O 50 minutes (6)

O 60 minutes (7)

O 70 minutes (1 hr $10 \mathrm{~min})(8)$

O 80 minutes ( $1 \mathrm{hr} 20 \mathrm{~min})(9)$

O 90 minutes (1 hr $30 \mathrm{~min}$ ) (10)

O 100 minutes (1 hr $40 \mathrm{~min}$ ) (11)

O 110 minutes ( $1 \mathrm{hr} 50 \mathrm{~min}$ ) (12)

O 120 minutes (2 hrs) (13)

O 130 minutes (2 hrs $10 \mathrm{~min})$ (14)

O 140 minutes (2 hrs $20 \mathrm{~min}$ ) (15)

O 150 minutes (2 hrs $30 \mathrm{~min}$ ) (16)

O 160 minutes (2 hrs $40 \mathrm{~min}$ ) (17)

O 170 minutes (2 hrs $50 \mathrm{~min}$ ) (18)

O $180+$ minutes (3 hrs or more) (19)

Don't know/not sure (20)

Choose not to answer (21) 
Q350 This question is about the time you spent sitting on weekdays during the last 7 days. Include time spent at work, at home, while doing course work and during leisure time. This may include time spent sitting at a desk, visiting friends, reading or sitting or lying down to watch television. During the last 7 days, how much time did you spend sitting on a week day?

O 10 minutes (1)

O 20 minutes (2)

O 30 minutes (3)

O 40 minutes (4)

O 50 minutes (5)

O 60 minutes (6)

O 70 minutes $(1 \mathrm{hr} 10 \mathrm{~min})(7)$

O 80 minutes ( $1 \mathrm{hr} 20 \mathrm{~min})(8)$

O 90 minutes (1 hr $30 \mathrm{~min})(9)$

O 100 minutes (1 hr $40 \mathrm{~min})(10)$

O 110 minutes ( $1 \mathrm{hr} 50 \mathrm{~min})(11)$

O 120 minutes ( 2 hrs) (12)

O 130 minutes (2 hrs $10 \mathrm{~min})(13)$

O 140 minutes (2 hrs $20 \mathrm{~min})(14)$

O 150 minutes (2 hrs $30 \mathrm{~min})(15)$

O 160 minutes ( $2 \mathrm{hrs} 40 \mathrm{~min})(16)$

O 170 minutes (2 hrs $50 \mathrm{~min})$ (17)

O $180+$ minutes ( 3 hrs or more) (18)

O Don't know/not sure (19)

Choose not to answer (20)

Q352 Think about the time you spent doing any physical activities specifically designed to strengthen your muscles such as lifting weights, push-ups or sit-ups. Include all such activities even if you have reported them before.

Q354 During the last 7 days, how many days did you do any physical activities designed to strengthen muscles such as lifting weights, push-ups or sit-ups?

O 0 days (1)

O 1 day (2)

O 2 days (3)

O 3 days (4)

O 4 days (5)

O 5 days $(6)$

O 6 days (7)

O 7 days $(8)$

Choose not to answer (9) 
Q356 How much time did you usually spend doing strength training activities on one of those days?

Did not do strength activities (1)

O 10 minutes (2)

O 20 minutes (3)

O 30 minutes (4)

O 40 minutes (5)

O 50 minutes (6)

O 60 minutes (7)

O 70 minutes $(1 \mathrm{hr} 10 \mathrm{~min})(8)$

O 80 minutes ( $1 \mathrm{hr} 20 \mathrm{~min})(9)$

O 90 minutes (1 hr $30 \mathrm{~min})(10)$

O 100 minutes (1 hr $40 \mathrm{~min})(11)$

O 110 minutes ( $1 \mathrm{hr} 50 \mathrm{~min})(12)$

O 120 minutes ( $2 \mathrm{hrs})(13)$

O 130 minutes (2 hrs $10 \mathrm{~min})(14)$

O 140 minutes (2 hrs $20 \mathrm{~min})(15)$

O 150 minutes (2 hrs $30 \mathrm{~min})(16)$

O 160 minutes ( $2 \mathrm{hrs} 40 \mathrm{~min})(17)$

O 170 minutes (2 hrs $50 \mathrm{~min})(18)$

O $180+$ minutes ( 3 hrs or more) (19)

O Don't know/not sure (20)

Choose not to answer (21)

Q358 Sustainable Transportation (ST) includes any way of traveling other than driving by yourself. So walking, biking, public transportation (bus/subway/train) and carpooling are all types of ST. Choose the one statement that best reflects your situation:

O I do not regularly use ST and I do not intend to start within the next 6 months (1)

O I am thinking about regularly using ST in the next 6 months (2)

$\mathrm{O}$ I am planning to regularly use ST in the next 30 days (3)

O I regularly use ST and have been for less than 6 months (4)

O I regularly use ST and have been doing so for 6 months or more (5)

O Choose not to answer (6) 
Q360 Here are some advantages and disadvantages of using sustainable transportation (ST). ST includes walking, biking, public transportation, and carpooling to travel, instead of driving alone. HOW IMPORTANT is each item to you in your decisions about whether or not to use ST?

\begin{tabular}{|c|c|c|c|c|c|c|}
\hline & $\begin{array}{c}\text { Not } \\
\text { important } \\
\text { (1) }\end{array}$ & $\begin{array}{c}\text { Slightly } \\
\text { important } \\
\text { (2) }\end{array}$ & $\begin{array}{c}\text { Somewhat } \\
\text { important } \\
\text { (3) }\end{array}$ & $\begin{array}{c}\text { Very } \\
\text { important } \\
\text { (4) }\end{array}$ & $\begin{array}{l}\text { Extremely } \\
\text { important } \\
\text { (5) }\end{array}$ & $\begin{array}{l}\text { Choose } \\
\text { not to } \\
\text { answer } \\
\text { (6) }\end{array}$ \\
\hline $\begin{array}{l}\text { ST is worth } \\
\text { the extra } \\
\text { effort (1) }\end{array}$ & 0 & 0 & 0 & 0 & 0 & 0 \\
\hline $\begin{array}{c}\text { ST is not } \\
\text { practical } \\
\text { from where I } \\
\text { live (2) }\end{array}$ & 0 & 0 & 0 & 0 & 0 & 0 \\
\hline $\begin{array}{l}\text { I am proud } \\
\text { that I can } \\
\text { help the } \\
\text { environment } \\
\text { by using ST } \\
\text { (3) }\end{array}$ & 0 & 0 & 0 & 0 & 0 & 0 \\
\hline $\begin{array}{l}\text { ST can be a } \\
\text { hassle (4) }\end{array}$ & 0 & 0 & 0 & 0 & 0 & 0 \\
\hline $\begin{array}{l}\text { Using ST is } \\
\text { part of being } \\
\text { green }(5)\end{array}$ & 0 & 0 & 0 & 0 & 0 & 0 \\
\hline $\begin{array}{l}\text { I save time } \\
\text { by driving } \\
\text { by myself } \\
\text { (6) }\end{array}$ & 0 & $\bigcirc$ & 0 & 0 & 0 & 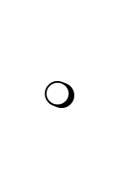 \\
\hline $\begin{array}{l}\text { ST is one } \\
\text { way to } \\
\text { improve my } \\
\text { own health } \\
\text { and the } \\
\text { health of the } \\
\text { planet (7) }\end{array}$ & 0 & 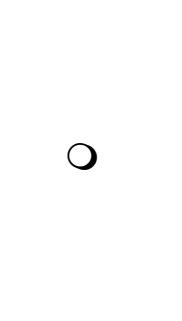 & 0 & 0 & 0 & 0 \\
\hline $\begin{array}{l}\text { ST would be } \\
\text { too difficult } \\
\text { (8) }\end{array}$ & 0 & 0 & 0 & 0 & 0 & 0 \\
\hline $\begin{array}{c}\text { ST can save } \\
\text { me money } \\
\text { (gas/parking) } \\
\text { (9) }\end{array}$ & O & 0 & 0 & 0 & 0 & 0 \\
\hline $\begin{array}{l}\text { ST can be } \\
\text { too much }\end{array}$ & 0 & 0 & 0 & 0 & O & O \\
\hline
\end{tabular}


trouble (10)

Q362 ST means walking, biking, public transportation, and carpooling to travel, instead of driving alone. HOW CONFIDENT are you that you would use ST, even when...

\begin{tabular}{|c|c|c|c|c|c|c|}
\hline $\begin{array}{c}\text { Not at all } \\
\text { confident } \\
(1)\end{array}$ & $\begin{array}{c}\text { Not very } \\
\text { confident } \\
(2)\end{array}$ & $\begin{array}{c}\text { Somewhat } \\
\text { confident } \\
(3)\end{array}$ & $\begin{array}{c}\text { Very } \\
\text { confident } \\
(4)\end{array}$ & $\begin{array}{c}\text { Extremely } \\
\text { confident } \\
(5)\end{array}$ & $\begin{array}{c}\text { Choose } \\
\text { not to } \\
\text { answer } \\
(6)\end{array}$ \\
\hline $\begin{array}{c}\text { I am running } \\
\text { late (1) } \\
\text { I have } \\
\text { errands to } \\
\text { run (2) } \\
\text { I am tired } \\
\text { (3) }\end{array}$ & 0 & 0 & 0 & 0 & 0 & 0 \\
$\begin{array}{c}\text { I have other } \\
\text { people to } \\
\text { pick up (4) }\end{array}$ & 0 & 0 & 0 & 0 & 0 & 0 \\
$\begin{array}{c}\text { It is } \\
\text { inconvenient } \\
\text { (5) }\end{array}$ & 0 & 0 & 0 & 0 & 0 & 0 \\
\hline
\end{tabular}

Q364 Do you live on campus?

$\bigcirc$ Yes (1)

No (2)

If Yes Is Selected, Then Skip To End of Block 
Q366 Thinking about the number of round-trips you travel to and from campus, please answer the following: In a typical week, how many round-trip trips to and from campus do you travel?

O None (1)

O $1(2)$

○ 2 (3)

○ $3(4)$

○ (5)

O $5(6)$

○ $6(7)$

O 7 (8)

More than 7 (9)

Choose not to answer (10)

Q368 Of these, how many do you drive alone?

O None (1)

O $1(2)$

○ 2 (3)

○ $3(4)$

○ 4 (5)

$5(6)$

○ $6(7)$

○ 7 (8)

O More than 7 (9)

Choose not to answer (10)

Q370 Of those, how many do you carpool (at least 2 people per car)?

O None (1)

○ 1 (2)

○ 2 (3)

○ 3 (4)

○ (5)

○ $5(6)$

O $6(7)$

○ $7(8)$

More than 7 (9)

Choose not to answer (10) 
Q372 Of these, how many do you bike, skate, skateboard, or use a scooter?

O None (1)

○ 1 (2)

○ $2(3)$

○ 3 (4)

○ (5)

○ $5(6)$

○ $6(7)$

○ $7(8)$

More than 7 (9)

Choose not to answer (10)

Q374 Of these, how many do you walk?

O None (1)

○ 1 (2)

○ 2 (3)

○ 3 (4)

○ $4(5)$

○ $5(6)$

○ $6(7)$

○ 7 (8)

O More than 7 (9)

Choose not to answer (10)

Q376 Of these, how many do you use public transportation (train, bus, subway)?

O None (1)

○ 1 (2)

○ 2 (3)

○ $3(4)$

○ $4(5)$

○ $5(6)$

○ $6(7)$

○ $7(8)$

O More than 7 (9)

Choose not to answer (10)

Q324 Have you taken this survey before for another class this semester?

$\bigcirc$ Yes (1)

No (2) 
Q320 Thank you for completing the survey! Please click on the link below to submit information for class credit.

https://utk.co1.qualtrics.com/SE/?SID=SV_cUa1S3pbEfmq4Fn 


\section{APPENDIX B:}

Analysis of Normality of Data

\begin{tabular}{|l|c|c|c|c|}
\hline & Skewness & & Kurtosis & \\
\hline & Statistic & Std. Error & Statistic & Std. Error \\
\hline $\begin{array}{l}\text { Cups of Fruits \& } \\
\text { Vegetables }\end{array}$ & 0.987 & 0.073 & 1.354 & .146 \\
\hline $\begin{array}{l}\text { Moderate Physical } \\
\text { Activity Minutes } \\
\text { Weekly }\end{array}$ & 2.917 & 0.074 & 3.942 & .147 \\
\hline
\end{tabular}




\section{BIBLIOGRAPHY:}

1. Greene GW, Schembre SM, White AA, Hoerr SL, Lohse B, Shoff S, Horacek T, Riebe D, Patterson J, Phillips BW, et al. Identifying clusters of college students at elevated health risk based on eating and exercise behaviors and psychosocial determinants of body weight. J Am Diet Assoc 2011;111(3):394400. doi: 10.1016/j.jada.2010.11.011.

2. Kattelmann KK, Bredbenner CB, White AA, Greene GW, Hoerr SL, Kidd T, Colby S, Horacek TM, Phillips BW, Koenings MM, et al. The effects of Young Adults Eating and Active for Health (YEAH): a theory-based Webdelivered intervention. J Nutr Educ Behav 2014;46(6):S27-41. doi: 10.1016/j.jneb.2014.08.007.

3. La Mela C, Maglietta M, Caini S, Casu GP, Lucarelli S, Mori S, Ruggiero GM. Perfectionism, weight and shape concerns, and low self-esteem: Testing a model to predict bulimic symptoms. Eat Behav 2015;19:155-8. doi: 10.1016/j.eatbeh.2015.09.002.

4. Fitzsimmons-Craft EE, Harney MB, Koehler LG, Danzi LE, Riddell MK, Bardone-Cone AM. Explaining the relation between thin ideal internalization and body dissatisfaction among college women: the roles of social comparison and body surveillance. Body Image 2012;9(1):43-9. doi:

10.1016/j.bodyim.2011.09.002.

5. Grossbard JR, Neighbors C, Larimer ME. Perceived norms for thinness and muscularity among college students: what do men and women really want? Eat Behav 2011;12(3):192-9. doi: 10.1016/j.eatbeh.2011.04.005.

6. Frederick DA, Sandhu G, Morse PJ, Swami V. Correlates of appearance and weight satisfaction in a U.S. National Sample: Personality, attachment style, television viewing, self-esteem, and life satisfaction. Body Image 2016;17:191203. doi: 10.1016/j.bodyim.2016.04.001.

7. Hartmann C, Siegrist M. A longitudinal study of the relationships between the Big Five personality traits and body size perception. Body Image 2015;14:6771. doi: 10.1016/j.bodyim.2015.03.011.

8. Heatherton TF. Body Dissatisfaction, Self-Focus, and Dieting Status Among Women. Psychology of Addictive Behavior 1997;7(4):225-31.

9. Neighbors LA, Sobal J. Prevalence and magnitude of body weight and shape dissatisfaction among university students. Eat Behav 2007;8(4):429-39. doi: 10.1016/j.eatbeh.2007.03.003.

10. MacNeill LP, Best LA. Perceived current and ideal body size in female undergraduates. Eat Behav 2015;18:71-5. doi: 10.1016/j.eatbeh.2015.03.004.

11. Belohlavek R, Sigmund E, Zacpal J. Evaluation of IPAQ questionnaires supported by formal concept analysis $i$. Information Sciences 2011;181(10):1774-86. doi: 10.1016/j.ins.2010.04.011.

12. Yaroch AL, Tooze J, Thompson FE, Blanck HM, Thompson OM, ColonRamos U, Shaikh AR, McNutt S, Nebeling LC. Evaluation of three short dietary instruments to assess fruit and vegetable intake: the National Cancer Institute's food attitudes and behaviors survey. J Acad Nutr Diet 2012;112(10):1570-7. doi: 10.1016/j.jand.2012.06.002. 
13. Gropper SS, Arsiwalla DD, Lord DC, Huggins KW, Simmons KP, Ulrich PV. Associations among eating regulation and body mass index, weight, and body fat in college students: The moderating role of gender. Eating Behaviors 2014;15(2):321-7. doi: 10.1016/j.eatbeh.2014.04.002.

14. Gropper SS, Simmons KP, Connell LJ, Ulrich PV. Changes in body weight, composition, and shape: a 4-year study of college students. Applied Physiology, Nutrition, and Metabolism 2012;37(6):1118-23. doi: 10.1139/h2012-139.

15. Green KL CR, Polivy J, Cooper K, Liu L, Leiter L,Heatherton T. Weight disstisfaction and weight loss attempts among Canadian adults. CAN MED ASSOC J 1997; 157:S17-S25.

16. Brunt A RY, Zhong L. Differences in Dietary Patterns Among College Students According to Body Mass Index Journal of American College Health 2008;56(6):629-34.

17. Gunnare NA, Silliman K, Morris MN. Accuracy of self-reported weight and role of gender, body mass index, weight satisfaction, weighing behavior, and physical activity among rural college students. Body Image 2013;10(3):40610. doi: 10.1016/j.bodyim.2013.01.006.

18. Pope L, Hansen D, Harvey J. Examining the Weight Trajectory of College Students. J Nutr Educ Behav 2017;49(2):137-41 e1. doi: 10.1016/j.jneb.2016.10.014.

19. Cluskey M, Grobe D. College weight gain and behavior transitions: male and female differences. J Am Diet Assoc 2009;109(2):325-9. doi: 10.1016/j.jada.2008.10.045.

20. Kelly MC, Latner JD. Evaluating patterns of weight and body composition change among college women. Eat Behav 2015;17:157-62. doi: 10.1016/j.eatbeh.2015.01.016.

21. Webb JB, Butler-Ajibade P, Robinson SA, Lee SJ. Weight-gain misperceptions and the third-person effect in Black and White college-bound females: potential implications for healthy weight management. Eat Behav 2013;14(3):245-8. doi: 10.1016/j.eatbeh.2013.03.002.

22. Lloyd-Richardson EE, Bailey S, Fava JL, Wing R, Tobacco Etiology Research N. A prospective study of weight gain during the college freshman and sophomore years. Prev Med 2009;48(3):256-61. doi: 10.1016/j.ypmed.2008.12.009.

23. Racette SB, Deusinger SS, Strube MJ, Highstein GR, Deusinger RH. Changes in weight and health behaviors from freshman through senior year of college. $\mathrm{J}$ Nutr Educ Behav 2008;40(1):39-42. doi: 10.1016/j.jneb.2007.01.001.

24. Hendrickse J, Arpan LM, Clayton RB, Ridgway JL. Instagram and college women's body image: Investigating the roles of appearance-related comparisons and intrasexual competition. Computers in Human Behavior 2017;74:92-100. doi: 10.1016/j.chb.2017.04.027.

25. Lin L, DeCusati F. Muscle Dysmorphia and the Perception of Men's Peer Muscularity Preferences. Am J Mens Health 2016;10(6):NP78-NP88. doi: $10.1177 / 1557988315598367$. 
26. Jackson L. Physical attractiveness: A sociocultural perspective. Edtion ed. Body image: A Handbook of theory, research, and clinical

practice. New York: The Guilford Press., 2002:13-21.

27. American College Health Association. American College Heath Association 2016.

28. Glaurert R RG, Fink Bernhard, Grammer K Body dissatisfaction and attentional bias to thin bodies. Int J Eat Disord 2010(43):42-9.

29. van den Berg P, Paxton SJ, Keery H, Wall M, Guo J, Neumark-Sztainer D. Body dissatisfaction and body comparison with media images in males and females. Body Image 2007;4(3):257-68. doi: 10.1016/j.bodyim.2007.04.003.

30. Neumark-Sztainer D, Paxton SJ, Hannan PJ, Haines J, Story M. Does body satisfaction matter? Five-year longitudinal associations between body satisfaction and health behaviors in adolescent females and males. J Adolesc Health 2006;39(2):244-51. doi: 10.1016/j.jadohealth.2005.12.001.

31. Sira N, White CP. Individual and familial correlates of body satisfaction in male and female college students. J Am Coll Health 2010;58(6):507-14. doi: 10.1080/07448481003621742.

32. Tiggemann M. Body dissatisfaction and adolescent self-esteem: prospective findings. Body Image 2005;2(2):129-35. doi: 10.1016/j.bodyim.2005.03.006.

33. McCabe MP, Ricciardelli LA. Body image dissatisfaction among males across the lifespan. Journal of Psychosomatic Research 2004;56(6):675-85. doi: 10.1016/s0022-3999(03)00129-6.

34. Ridgeway RT, Tylka TL. College Men's Perceptions of Ideal Body Composition and Shape. Psychology of Men \& Masculinity 2005;6(3):209-20. doi: 10.1037/1524-9220.6.3.209.

35. Palmer J. Characteristics of Male and Female College Students with Weight Dissatisfaction: A Secondary Data Analysis Masters Thesis 2012.

36. Jaworowska A, Bazylak G. An outbreak of body weight dissatisfaction associated with self-perceived BMI and dieting among female pharmacy students. Biomed Pharmacother 2009;63(9):679-92. doi: 10.1016/j.biopha.2008.08.005.

37. Harris N, Gee D, d'Acquisto D, Ogan D, Pritchett K. Eating disorder risk, exercise dependence, and body weight dissatisfaction among female nutrition and exercise science university majors. J Behav Addict 2015;4(3):206-9. doi: 10.1556/2006.4.2015.029.

38. Almlund M, Duckworth AL, Heckman J, Kautz T. Personality Psychology and Economics. 2011;4:1-181. doi: 10.1016/b978-0-444-53444-6.00001-8.

39. Gosling SD, Rentfrow PJ, Swann WB. A very brief measure of the Big-Five personality domains. Journal of Research in Personality 2003;37(6):504-28. doi: 10.1016/s0092-6566(03)00046-1.

40. Golsteyn B, Schildberg-Hörisch H. Challenges in research on preferences and personality traits: Measurement, stability, and inference. Journal of Economic Psychology 2017. doi: 10.1016/j.joep.2017.03.001.

41. Thoma ME, Hediger ML, Sundaram R, Stanford JB, Peterson CM, Croughan MS, Chen Z, Buck Louis GM, Group ESW. Comparing apples and pears: 
women's perceptions of their body size and shape. J Womens Health (Larchmt) 2012;21(10):1074-81. doi: 10.1089/jwh.2012.3634.

42. Kvalem IL, von Soest T, Roald HE, Skolleborg KC. The interplay of personality and negative comments about appearance in predicting body image. Body Image 2006;3(3):263-73. doi: 10.1016/j.bodyim.2006.04.002.

43. Allen MS, Walter EE. Personality and body image: A systematic review. Body Image 2016;19:79-88. doi: 10.1016/j.bodyim.2016.08.012.

44. Benford K, Swami V. Body image and personality among British men: associations between the Big Five personality domains, drive for muscularity, and body appreciation. Body Image 2014;11(4):454-7. doi:

10.1016/j.bodyim.2014.07.004.

45. Roberts A, Good E. Media images and female body dissatisfaction: the moderating effects of the Five-Factor traits. Eat Behav 2010;11(4):211-6. doi: 10.1016/j.eatbeh.2010.04.002.

46. Sutin A.R. TA. Five-Factor Model Personality Traits and the Objective and Subjective Experience of Body Weeight. Journal of Personaliry 2016;84(1):102-12.

47. Paans NP, Bot M, Gibson-Smith D, Van der Does W, Spinhoven P, Brouwer I, Visser M, Penninx BW. The association between personality traits, cognitive reactivity and body mass index is dependent on depressive and/or anxiety status. J Psychosom Res 2016;89:26-31. doi: 10.1016/j.jpsychores.2016.07.013.

48. Downes L. Physical Activity and Dietary Habits of College Students. The Journal for Nurse Practitioners 2015;11(2):192-8.e2. doi: 10.1016/j.nurpra.2014.11.015.

49. Caspersen CJ, Powell, K.E., Christenson G.M.,. Physical activity, exercise, and physical fitness: definitions and distinctions for health-related research Public Health Reports 1985;100(2):126.

50. Ingledew DK SG. Effects of body mass and body image on exercise motives in adolescence. Psychology of Sport and Exercise 2002;3:323-38.

51. Hausenblas H DD. Comparison of body image between athletes and nonathletes: a meta-analytic review. Journal of Applied Sport Psychology 2002;13:329-39.

52. Anton S PM, Riley J Discrepancy between actual and ideal body images impact on eating and exercise behaviors Eat Behav 2000;1:153-60.

53. Kim J. Personality traits and body weight: Evidence using sibling comparisons. Soc Sci Med 2016;163:54-62. doi: 10.1016/j.socscimed.2016.06.054.

54. Wilson KE, Dishman RK. Personality and physical activity: A systematic review and meta-analysis. Personality and Individual Differences 2015;72:23042. doi: $10.1016 /$ j.paid.2014.08.023.

55. Lü W, Wang Z, Liu Y, Zhang H. Resilience as a mediator between extraversion, neuroticism and happiness, PA and NA. Personality and Individual Differences 2014;63:128-33. doi: 10.1016/j.paid.2014.01.015.

56. Elfhag K, Morey LC. Personality traits and eating behavior in the obese: poor self-control in emotional and external eating but personality assets in restrained eating. Eat Behav 2008;9(3):285-93. doi: 10.1016/j.eatbeh.2007.10.003. 
57. Ha EJ, Caine-Bish N. Effect of nutrition intervention using a general nutrition course for promoting fruit and vegetable consumption among college students. J Nutr Educ Behav 2009;41(2):103-9. doi: 10.1016/j.jneb.2008.07.001.

58. Nix E, Wengreen HJ. Social approval bias in self-reported fruit and vegetable intake after presentation of a normative message in college students. Appetite 2017. doi: 10.1016/j.appet.2017.05.045.

59. Goldberg L. R. SLA. Personality traits and eating habits: the assessment of food preferences in a large community sample. Personality and Individual Differences 2002;32:49-65.

60. Zullig KJ, Matthews-Ewald MR, Valois RF. Weight perceptions, disordered eating behaviors, and emotional self-efficacy among high school adolescents. Eat Behav 2016;21:1-6. doi: 10.1016/j.eatbeh.2015.11.007.

61. Lemon SC, Rosal MC, Zapka J, Borg A, Andersen V. Contributions of weight perceptions to weight loss attempts: differences by body mass index and gender. Body Image 2009;6(2):90-6. doi: 10.1016/j.bodyim.2008.11.004.

62. Sampasa-Kanyinga H, Hamilton, H.A., Willmore J., Chaput J.-P. . Perceptions and attitudes about body weight and adherence to the physical activity recommendations among adolescents: the moderating role of body mass index. . Public Health 2017;146:75-83. doi: 10.1016/j.puhe.2017.01.002.

63. Liu S, Fu MR, Hu SH, Wang VY, Crupi R, Qiu JM, Cleland C, D'Eramo Melkus G. Accuracy of body weight perception and obesity among Chinese Americans. Obes Res Clin Pract 2016;10 Suppl 1:S48-S56. doi: 10.1016/j.orcp.2015.04.004.

64. Tanenbaum HC, Felicitas JQ, Li Y, Tobias M, Chou CP, Palmer PH, SpruijtMetz D, Reynolds KD, Anderson Johnson C, Xie B. Overweight Perception: Associations with Weight Control Goals, Attempts, and Practices among Chinese Female College Students. J Acad Nutr Diet 2016;116(3):458-66. doi: 10.1016/j.jand.2015.06.383.

65. Gibbs HD, Pacheco C, Yeh HW, Daley C, Greiner KA, Choi WS. Accuracy of Weight Perception Among American Indian Tribal College Students. Am J Prev Med 2016;51(5):e139-e44. doi: 10.1016/j.amepre.2016.06.002.

66. Vassend O, Skrondal A. The NEO personality inventory revised (NEO-PI-R): Exploring the measurement structure and variants of the five-factor model. Personality and Individual Differences 2011;50(8):1300-4. doi: 10.1016/j.paid.2011.03.002.

67. Wolfe WS, Frongillo EA, Cassano PA. Evaluating Brief Measures of Fruit and Vegetable Consumption Frequency and Variety. Journal of the American Dietetic Association 2001;101(3):311-8. doi: 10.1016/s0002-8223(01)00081-5.

68. 2005. Internet: http://www.ipaq.ki.se/scoring.pdf. .

69. Rzewinicki R VAY, De Bourdeaudhuij. Addressing overreporting on the International Physical Activity Questionnaire (IPAQ) telephone survey with a population sample. Public Health Nutr 2003;6(3):299-305.

70. Organization WH. WHO : Global Database on Body Mass Index.pdf.

71. Iglewicz B. HD. Volume 16: How to Detect and Handle Outliers. Edtion ed. In: Mykytka EF, ed. The ASQC Basic References in Quality Control 1993. 
72. Leonard D. Constructing Normalcy Edtion ed. The Disability Studies Reader Routledge, 2006.

73. Thompson VJ, Bachman CM, Baranowski T, Cullen KW. Self-efficacy and norm measures for lunch fruit and vegetable consumption are reliable and valid among fifth grade students. J Nutr Educ Behav 2007;39(1):2-7. doi: 10.1016/j.jneb.2006.06.006.

74. Blouin A GG. Body image and steroid us in male bodybuilders International Journal of Eating Disorders 1994;18(2):159-65.

75. Johnson JA. Measuring thirty facets of the Five Factor Model with a 120-item public domain inventory: Development of the IPIP-NEO-120. Journal of Research in Personality 2014;51:78-89. doi: 10.1016/j.jrp.2014.05.003.

76. Raynor HA, Champagne CM. Position of the Academy of Nutrition and Dietetics: Interventions for the Treatment of Overweight and Obesity in Adults. J Acad Nutr Diet 2016;116(1):129-47. doi: 10.1016/j.jand.2015.10.031. 